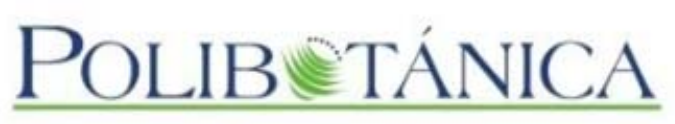

\title{
Polibotánica
}

ISSN electrónico: 2395-9525

polibotanica@gmail.com

Instituto Politécnico Nacional

México

http:www.polibotanica.mx

\section{CAMBIOS EN LA SUPERFICIE DE ÁREAS VERDES URBANAS EN DOS ALCALDÍAS DE LA CIUDAD DE MÉXICO ENTRE 1990-2015}

\section{CHANGES IN THE SURFACE OF GREEN AREAS IN TWO CITY HALLS OF MEXICO CITY BETWEEN 1990-2015}

Maldonado-Bernabé, G.; A. Chacalo-Hilu, I. Nava-Bolaños, R.M. Meza-Paredes, y A.Y. Zaragoza-Hernández.

CAMBIOS EN LA SUPERFICIE DE ÁREAS VERDES URBANAS EN DOS ALCALDÍAS DE LA CIUDAD DE MÉXICO ENTRE 1990-2015.

CHANGES IN THE SURFACE OF GREEN AREAS IN TWO CITY HALLS OF MEXICO CITY BETWEEN 1990-2015.

POLIB eTÁNICA

Instituto Politécnico Nacional
Núm. 48: 205-230 México. Julio 2019

DOI: $10.18387 /$ polibotanica.48.15

(c) (i) Este es un artículo de acceso abierto bajo la licencia Creative Commons 4.0 Atribución-No Comercial (CC BY-NC 4.0 Internacional). 


\section{CAMBIOS EN LA SUPERFICIE DE ÁREAS VERDES URBANAS EN DOS} ALCALDÍAS DE LA CIUDAD DE MÉXICO ENTRE 1990-2015.

\section{CHANGES IN THE SURFACE OF GREEN AREAS IN TWO CITY HALLS OF MEXICO CITY BETWEEN 1990-2015.}

Maldonado-Bernabé, G.;

A. Chacalo-Hilu, I. Nava-

Bolaños, R.M. Meza-Paredes,

y A.Y. Zaragoza-Hernández

CAMBIOS EN LA

SUPERFICIE DE ÁREAS

VERDES URBANAS EN DOS

ALCALDÍAS DE LA CIUDAD

DE MÉXICO ENTRE 19902015

CHANGES IN THE

SURFACE OF GREEN

AREAS IN TWO CITY

HALLS OF MEXICO CITY

BETWEEN 1990-2015

\section{POLIBETÁNICA}

Instituto Politécnico Nacional

Núm. 48: 205-230. Julio 2019

DOI:

10.18387/polibotanica.48.15

\author{
G. Maldonado-Bernabé / G.Maldo_Biol@outlook.com \\ Universidad Nacional Autónoma de México
}

A. Chacalo-Hilu

Universidad Autónoma Metropolitana, Azcapozalco

I. Nava-Bolaños

Instituto de Investigaciones Económicas, UNAM

R.M. Meza-Paredes

Facultad de Arquitectura, UNAM

A.Y. Zaragoza-Hernández

Colegio de Postgraduados, Campus Montecillo, México

RESUMEN: Las áreas verdes urbanas (AVU) tienen un papel fundamental en la sostenibilidad urbana debido a los diversos beneficios ambientales y sociales que prestan, es por ello que toda ciudad que pretenda ser moderna, segura, incluyente y sustentable debe garantizar el acceso y disponibilidad de estos espacios para sus habitantes (Procuraduria Ambiental y de Ordenamiento Territorial, 2010). La ciudad de México se promueve como una ciudad en tránsito a la sostenibilidad por lo que ha puesto en marcha distintos planes y acciones enfocados al cuidado ambiental, dentro de los que se encuentran las AVU. Debido a esto, el presente trabajo tuvo como objetivo principal comparar, usando sistemas de información geográfica (SIG) y censos poblacionales de INEGI (Instituto Nacional de Estadística y Geografía), la superficie de AVU existentes en dos alcaldías de la ciudad entre 1990 y 2015. La información de INEGI se utilizó para conocer la situación social de cada alcaldía en las fechas de estudio. Los resultados muestran que, si bien, las brechas sociales han disminuido en este periodo, existen grandes diferencias en la superficie y calidad de AVU entre ambas alcaldías, por lo que el objetivo de ser una ciudad ambientalmente sustentable aún no se cumple en la CDMX.

Palabras clave: Áreas verdes urbanas, Sistemas de Información Geográfica, sostenibilidad urbana, Ciudad de México.

ABSTRACT: The urban green areas (AVU) have a fundamental role in urban sustainability due to the diverse environmental and social benefits that they provide, that is why every city that pretends to be modern, safe, inclusive and sustainable must guarantee the access and availability of these spaces for its inhabitants (Procuraduria Ambiental y de Ordenamiento Territorial, 2010). Mexico City is promoted as a city in transit to sustainability, which is why it has launched various plans and actions focused on environmental care, including the AVU. Due to this, the main objective of this study was to compare, using geographic information systems (GIS) and population censuses of INEGI (National Institute of Statistics and Geography), the area of AVU existing in two city halls of the city between 1990 and 2015 The INEGI information was used to 
know the social situation of each mayor's office on the study dates. The results show that, although social gaps have decreased in this period, there are large differences in the surface and quality of AVU between both municipalities, so the goal of being an environmentally sustainable city is not yet met in the CDMX.

Key words: Urban Green areas, Geografical Information Sistem, Sustentability, México City.

\section{INTRODUCCIÓN}

En la actualidad la mayoría de la población mundial se concentra en las ciudades, esto implica que la mancha urbana se expanda, y que mucho del terreno libre sea destinado al servicio de los usos urbanos (Departamento de Ordenación del Territorio y Medio Ambiente, 2003). Este gran crecimiento urbano se debe a que estas áreas aportan cerca del $80 \%$ de los ingresos a cada país (UnHabitatIII, 2016). Para mantener este ritmo productivo, es necesaria una gran cantidad de trabajadores, por lo que los entornos urbanos resultan ser grandes generadores de empleos.

Sin embargo, esta concentración de personas genera una alta demanda de recursos y servicios, por lo que el ritmo de urbanización actual provoca la destrucción del medio natural, transformando el entorno de manera drástica (Sierra y Ramírez-Silva, 2010). Es por ello que actualmente existe una visión de alcanzar lo que se conoce como una "Ciudad sostenible", este concepto parte de la definición de "Desarrollo sostenible" el cual se refiere a "Aquel desarrollo que permite satisfacer las necesidades de las generaciones actuales, sin comprometer la capacidad de las generaciones futuras a satisfacer sus propias necesidades" (Gómez, 2014). Es decir, que en entornos urbanos lo que se busca es mantener el ritmo de producción a la vez que se eleva la calidad de vida, sin menguar los recursos naturales y sociales de los que depende esta alta producción.

Las áreas verdes urbanas (AVU) son espacios fundamentales para la sostenibilidad de las ciudades, debido a los beneficios ambientales, sociales y estéticos que prestan: mitigan ruidos, purifican el aire, permiten infiltración de agua, minimizan la erosión del suelo y ayudan a regular el microclima (López, 2013; Salvador, 2003).También benefician la salud pública, ya que existen enfermedades respiratorias, circulatorias y mentales relacionadas con la falta de estos espacios, como el agobio crónico, síndrome de inseguridad, soledad y falta de identidad (Kendal, Lee, Ramalho, Kathryn, y Bush, 2016; Salvador, 2003; Secretaría del Medio Ambiente, 2015; Sherer, 2003). Por otra parte, las altas tasas de urbanización, hacen que las AVU sean cada vez más importantes como espacios de interacción entre las personas y la naturaleza ya que generan oportunidades de cohesión social y realización de actividades al aire libre (Flores-Xolocotzi, 2012; Reyes y Figueroa, 2010). Estas son algunas de las razones por las cuales deben integrarse como parte fundamental de la planificación urbana, tal como lo han hecho países como Estados Unidos, Canadá, Francia e Inglaterra (Salvado, 2003).

Los beneficios ambientales y sociales de las AVU son razones por las que una ciudad que pretenda ser moderna, segura, incluyente y sustentable debe realizar esfuerzos para proveer y asegurar el libre acceso y disponibilidad de estos espacios para sus habitantes (Procuraduria Ambiental y de Ordenamiento Territorial, 2010). En este sentido distintas ciudades han tomado medidas para aumentar y mejorar las AVU, por ejemplo la ciudad de Málaga, España aumentó la superficie verde de 14 a 22 millones de metros cuadrados entre 2004 y 2012 (Observatorio de Medio Ambiente Urbano, 2015). Por otra parte, la ciudad de Pekín incrementó su superficie de AVU a raíz de los Juegos Olímpicos de 2008, y actualmente dispone de $44 \mathrm{~m}^{2}$ de área verde por cada habitante (medida expresada como $\mathrm{m}^{2} / \mathrm{H}$ ) (Hinojosa, 2014). Sin embargo, en Latinoamérica los procesos de urbanización explosiva y con poca planeación de la segunda mitad del siglo XX generaron escasez de espacios abiertos y recreativos (Reyes y Figueroa, 2010). En México, ciudades como Toluca y Mérida proveen 6 y $5 \mathrm{~m}^{2} / \mathrm{H}$ respectivamente (Galindo-Bianconi y Victoria-Uribe, 2012; Pérez-Medina y López-Falfán, 2015). En este sentido, algunos estudios indican que existe una correlación entre la clase social y el acceso a 
los beneficios ambientales, entre ellos las AVU (Bolin et al., 2000). Esto significa que una ciudad puede contener espacios con mayores beneficios y servicios ambientales que otros, lo cual tiene una fuerte influencia por la situación socioeconómica de sus habitantes.

La Ciudad de México (CDMX) tiene estudios que estiman la superficie total de AVU en su territorio, sin embargo, los criterios de evaluación difieren entre cada uno, por lo que estos estudios no pueden ser comparados. Por ejemplo, en 1987 se reportaron $2.4 \mathrm{~m}^{2} / \mathrm{H}$ (Benítez, Chacalo, y Barois, 1987), mientras que el estudio más reciente menciona que había $14 \mathrm{~m}^{2} / \mathrm{H}$ (Procuraduria Ambiental y de Ordenamiento Territorial, 2010). Sin embargo, el indicador de la relación de superficie de AVU por habitante, no explica aspectos como accesibilidad y distribución de estos espacios en la ciudad (Reyes y Figueroa, 2010). Por otra parte, a pesar de los estudios realizados, existen pocos inventarios de espacios verdes donde se encuentre de manera fehaciente la localización, superficie y vegetación presente en la Ciudad de México, lo que facilitaría la gestión, mantenimiento y planeación de estos espacios (Flores-Xolocotzi y Gonzáles-Guillen, 2010; Procuraduria Ambiental y de Ordenamiento Territorial, 2010).

Es por ello que el objetivo de este trabajo fue analizar las AVU de la Alcaldía Miguel Hidalgo $(\mathrm{AMH})$ e Iztacalco (AIZ) en términos de superficie y cantidad de vegetación en cuatro fechas (1990, 2000, 2010 y 2015). Adicionalmente se crearon mapas de ubicación de las AVU que permiten visualizar la distribución en el territorio de las alcaldías. Finalmente, los resultados se relacionan con la información de los censos de INEGI, con el fin de visualizar una posible relación entre la situación socio-económica y la cantidad y calidad de áreas verdes, sin embargo, es importante mencionar que en este estudio no se pretende determinar que exista o no una relación.

Como guía principal se buscó responder las siguientes preguntas: ¿Cuál es la superficie de área verde en las alcaldías?, ¿Cómo ha cambiado la vegetación de estos espacios?, ¿La cantidad de área verde es suficiente para la población de las alcaldías?

Este trabajo se conforma de una sección para contextualizar los esfuerzos que se han realizado en la CDMX en cuanto a AVU, seguido de una breve descripción de la metodología. A continuación, se hace una descripción de las zonas de estudio enfocada en la identificación de las principales características del espacio y de su población. Posteriormente se presentan los resultados y discusión, para finalmente cerrar con una sección de conclusiones.

\section{Ciudad de México en tránsito a la sostenibilidad}

La Ciudad de México (CDMX) es la capital de la República Mexicana, ocupa un territorio de $1,485 \mathrm{~km}^{2}$ (Instituto Nacional de Estadística Geografía e Informática, 2015a) se encuentra dividida en 16 alcaldías que son: Álvaro Obregón, Azcapotzalco, Benito Juárez, Coyoacán, Cuajimalpa, Cuauhtémoc, Gustavo A. Madero, Iztacalco, Iztapalapa, Magdalena Contreras, Miguel Hidalgo, Milpa Alta, Tláhuac, Tlalpan, Venustiano Carranza y Xochimilco (Instituto Nacional de Estadística Geografía e Informática, 2015a). El desarrollo de la CDMX fue paulatino, en 1930 la ciudad se concentraba en los territorios ocupados por las alcaldías: Benito Juárez, Cuauhtémoc, Venustiano Carranza y Miguel Hidalgo, razón por la cual a estas se les conoce como Ciudad Central (Bolivar y Caloca, 2011). Posteriormente se incorporaron otras zonas a través de distintos procesos de urbanización, de esta manera a partir de 1930 y hasta 1950 se integran las alcaldías que conforman el primer contorno, mientras que el segundo contorno se integra de 1950 a 1970, finalmente, se añade Milpa Alta, como parte del tercer contorno (figura 1) (Bolivar y Caloca, 2011). 


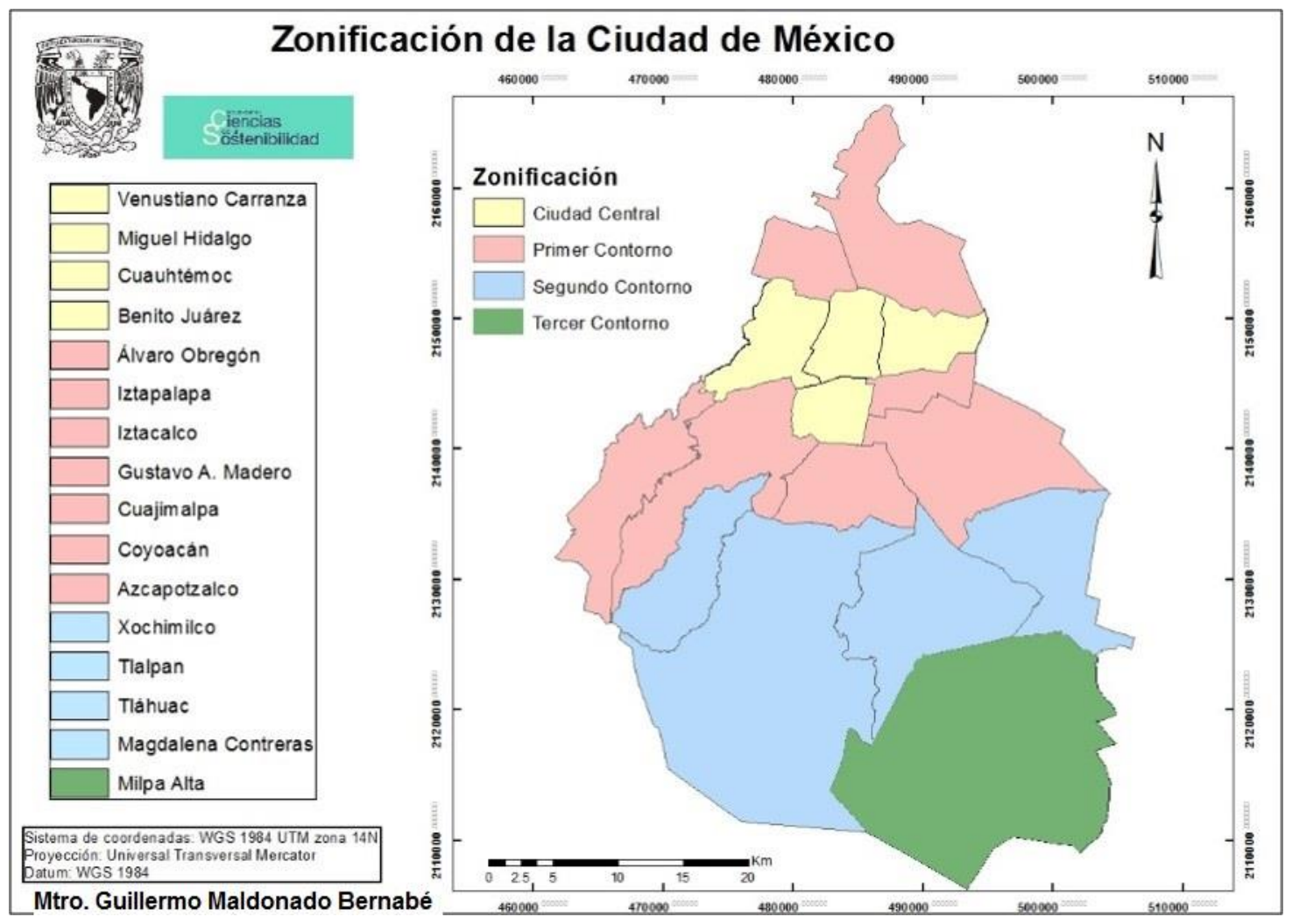

Fig. 1. Ciudad central y contornos de la Ciudad de México.

Elaboración propia.

La CDMX es de suma importancia para el país ya que genera grandes ingresos para el Producto Interno Bruto (PIB), en 1990 aportaba 23.9\% del total, sin embargo con el pasar de los años esta cifra bajó hasta 16.7\% en 2015 (Instituto Nacional de Estadística Geografía e Informática, 2002, 2017). La alta producción económica de la CDMX es una de las razones por las que la calidad de vida de su población se considera como de las mejores a nivel nacional, ya que, en general, la CDMX presenta bajos índices de marginación, pobreza y rezago social (Consejo Nacional de Evaluación de la Politica de Desarrollo Social, 2013). Respecto a las 32 entidades del país, ocupa el lugar 30 en porcentaje de población en pobreza y 31 en pobreza extrema (Consejo Nacional de Evaluación de la Politica de Desarrollo Social, 2013).

Sin embargo, a pesar de lo anterior, aún se deben atender ciertos problemas referentes a cobertura de servicios, mejora del transporte público, inseguridad, así como de disponibilidad y mejora de áreas verdes, entre otros. En este sentido, la CDMX impulsa una imagen de ciudad sostenible o en tránsito a la sostenibilidad, a partir de acciones para la protección del suelo de conservación; gestión y monitoreo de la calidad del aire; movilidad más eficiente; así como rescate y protección de espacios verdes (Secretaría del Medio Ambiente, 2015a). Dentro del criterio de AVU se han puesto en marcha distintos planes enfocados al cuidado, mantenimiento, recuperación y mejora de estos espacios (figura 2) ya que existen problemas de déficit y distribución del espacio público y AVU, además de que estos espacios presentan, en general, un significativo grado de abandono e invasión por parte del comercio informal y personas en situación de calle entre otros (Secretaría del Medio Ambiente, 2012a). 
Tabla 1. Planes y proyectos en beneficio de áreas verdes en la CDMX.

\begin{tabular}{|c|c|}
\hline Nombre & Objetivo \\
\hline $\begin{array}{l}\text { Plan Verde de la Ciudad de México } \\
\text { (Secretaría del Medio Ambiente, 2012b) }\end{array}$ & $\begin{array}{l}\text {...encaminar a la Ciudad a la sostenibilidad y garantizar que sea un } \\
\text { espacio adecuado para sus habitantes... }\end{array}$ \\
\hline $\begin{array}{l}\text { Programa de reforestación de la } \\
\text { CDMX (Secretaría del Medio Ambiente, } \\
\text { 2017). }\end{array}$ & Sanear y reforestar avenidas y camellones importantes de la ciudad \\
\hline $\begin{array}{l}\text { Ciudad verde, ciudad viva (Secretaría } \\
\text { del Medio Ambiente, 2016) }\end{array}$ & $\begin{array}{l}\text { Hacer de la ciudad una urbe verde, moderna, competitiva, exitosa y } \\
\text { con la mejor calidad de vida para sus habitantes }\end{array}$ \\
\hline $\begin{array}{l}\text { Ley de Salvaguarda del Patrimonio } \\
\text { Urbanístico Arquitectónico del DF } \\
\text { (Asamblea Legislativa del Distrito } \\
\text { Federal VI Legislatura, 2014). }\end{array}$ & $\begin{array}{l}\text { Salvaguardar los bienes inmuebles que sean declarados afectos al } \\
\text { Patrimonio Urbanístico Arquitectónico (PUA) (...) los cuales pueden } \\
\text { ser: calles, canales, chinampas, deportivos, huertos, jardines botánicos, } \\
\text { jardines, parques urbanos, paseos... }\end{array}$ \\
\hline $\begin{array}{lr}\text { Norma } & \text { Ambiental para el Distrito } \\
\text { Federal } & \text { NADF-001-RNAT-2015 } \\
\text { (Secretaría del Medio Ambiente, 2015b). }\end{array}$ & $\begin{array}{l}\text {...establece los requisitos, criterios, lineamientos y especificaciones } \\
\text { técnicas que deben cumplir las autoridades, personas físicas o morales } \\
\text { que realicen actividades de fomento, mejoramiento y mantenimiento } \\
\text { de áreas verdes públicas. }\end{array}$ \\
\hline
\end{tabular}

Elaboración propia.

Los programas de la figura 2 comparten el objetivo de tener una ciudad más verde con espacios abiertos que permitan la recreación, convivencia y fomenten las actividades al aire libre. En este sentido es natural pensar que las acciones realizadas se deben aplicar de igual manera en el territorio de la ciudad, para garantizar el acceso y disfrute de estos sitios para todos los habitantes.

Sin embargo, a través de redes sociales y periódicos abundan denuncias ciudadanas sobre tala indiscriminada y pérdida de áreas verdes en la ciudad, en donde se señala directamente a las obras vehiculares y habitacionales como responsables de la perdida, reducción y afectación de estos espacios (AlMomento.mx, 2017; Sánchez, 2015; Vera, 2014). Para cumplir con los objetivos planteados en esta investigación se utilizó una metodología basada en el análisis de fotografías aéreas e imágenes satelitales para la identificación de AVU, así como para determinar la superficie de estos espacios en ambas alcaldías. Por otra parte, la estimación del Índice de Vegetación Normalizado (NDVI, por sus siglas en inglés) permitió identificar las zonas al interior de las AVU con cobertura vegetal, con lo que fue posible hacer comparaciones entre cada año a fin de calcular la superficie de vegetación y detectar aumento o disminución en esta superficie. Para lo anterior se usaron el software, Qgis 2.12, ENVI y Google Earth.

Es importante recalcar que estas técnicas son de las más utilizadas para el análisis del cambio de la superficie terrestre y de la vegetación (Aguilar, Galindo, Fortanelli, y Contreras, 2010; Gonzales-Elizondo, Gonzales-Elizondo, y Cortes-Ortiz, 1993; Guzmán, López-García, y Manzo, 2008; Trucíos-Caciano, Estrada-Ávalos, Cerano-Paredes, y Rivera-Gonzáles, 2011).

En la CDMX existen distintas categorías de áreas verdes, entre las que están las AVA (áreas de valor ambiental); barrancas, suelo de conservación, áreas verdes urbanas entre otros. En este estudio se utilizó esta última categoría, la cual se dividió en dos, de acuerdo con las siguientes características.

- Áreas verdes de uso público: Jardines, parques, zonas infantiles y otros espacios de acceso público con bancas, corredores, gimnasio, sanitarios y otros, que fomenten actividades al aire libre. 
- Áreas verdes de vialidad: glorietas, camellones y jardineras con vegetación, cuya ubicación sea en la vía pública y que tengan funciones delimitantes (camellones) o meramente de contemplación.

En este trabajo se excluyen áreas de valor ambiental, suelo de conservación, barrancas, terrenos baldíos y otro tipo de espacios que, a pesar de tener vegetación, no todos son de acceso público o tienen funciones recreativas o uso en la vía pública. Sin embargo, existen barrancas en la alcaldía Miguel Hidalgo que se equiparon con mobiliario para uso recreativo, por lo cual a pesar de ser un AVA, están incluidas en los análisis.

Las fotografías aéreas son del año 2008, tienen resolución de 30x30 m por pixel, este material lo proporcionó la Procuraduría Ambiental y de Ordenamiento Territorial (PAOT). Las imágenes satelitales proceden de la misión Landsat y se captaron durante febrero (1990 y 2000) y marzo (2010 y 2015), antes de cualquier procedimiento se trataron en el software ENVI, con métodos de corrección radiométrica y atmosférica con el fin de disminuir errores de captación, pérdida de información o interferencia de la atmósfera, de manera que los cambios detectados sean atribuibles a verdaderos cambios en la superficie (Aguilar, Mora, y Vargas, 2014; Ancirasánchez y Treviño, 2015; Peña, 2007).

A través del uso de Qgis se identificaron las AVU con el apoyo de las fotografías aéreas, esto permitió contabilizar la cantidad de espacios y estimar la superficie total e individual de las AVU. Posteriormente se realizó el NDVI sobre las imágenes satelitales para visualizar la vegetación al interior de los espacios previamente identificados.

El resultado del NDVI es una imagen en la cual cada pixel puede tener valores que van de -1 a 1. Los valores por debajo del 0 se interpretan como zonas sin vegetación, mientras que los valores por arriba del 0 se consideran áreas con vegetación (Meneses-Tovar, 2011; Soria y Granados, 2005). Sin embargo, se utilizó las fotografías aéreas junto con la imagen del NDVI para realizar un muestreo de puntos aleatorios para identificar los valores reales de la vegetación. A partir de este muestreo, se reclasificó la imagen para visualizar en color verde las zonas con vegetación, y en amarillo aquellas sin vegetación (fig. 3).

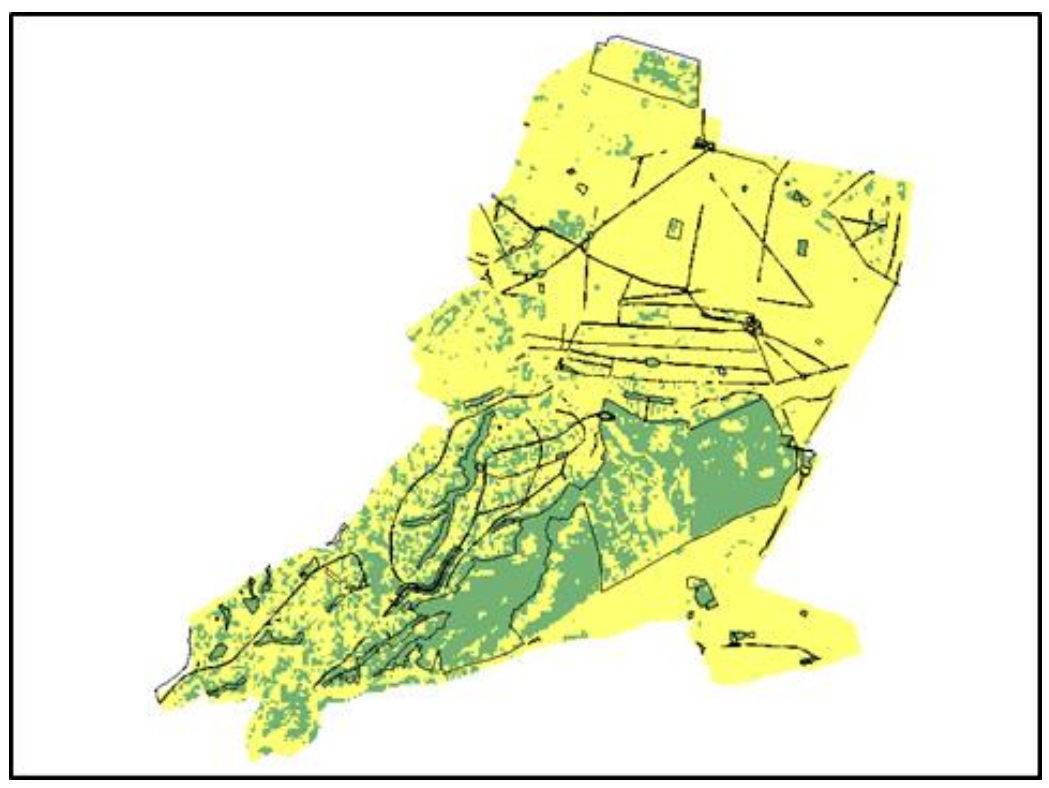

Fig. 2. Imagen de NDVI de la AMH. Que muestra en verde las zonas con vegetación y en amarillo las zonas sin vegetación. Elaboración propia. 
Finalmente, se utilizó esta información para comparar y cuantificar los cambios en las áreas verdes seleccionadas, en los años de estudio, a través de Qgis (Aldana, Anges, y Bosques, 2008; Guzmán et al., 2008; Hernández, Palacios, Otazo, y Mendoza, 2016; Ramos-Reyes, PalmaLópez, Ortiz-Solorio, Ortiz-Garcia, y Díaz-Padilla, 2004). Los valores resultantes del análisis pueden ser comparados siempre y cuando las imágenes se capten en el mismo periodo del año, ya que se reducen las diferencias de comportamiento de la vegetación a lo largo del año (Meneses-Tovar, 2011). En el caso de las imágenes que se utilizaron, las fechas de obtención son en la misma época del año bajo condiciones atmosféricas similares.

Por último, las condiciones de vida de la población en los años de estudio se consideran para discutir los resultados de las AVU en las dos alcaldías seleccionadas.

\section{Zonas de estudio}

Este trabajo se enfoca directamente en las áreas verdes de la ciudad, por ello se eligieron las alcaldías de Miguel Hidalgo (AMH) e Iztacalco (AIZ) principalmente por tener un tiempo de desarrollo similar por formar parte de la Ciudad Central (AMH) y del primer contorno Urbanizado (AIZ), por otra parte, como se menciona a continuación los procesos de urbanización en ambos territorios fue distinto lo que puede repercutir en la planeación y mejora de su territorio.

Estas alcaldías tienen un territorio aproximado de $46.9 \mathrm{~km}^{2}$ (AMH) y $23.3 \mathrm{~km}^{2}$ (AIZ) respectivamente ( 3 y $1.5 \%$ del territorio de la ciudad), se localizan en la zona norponiente y oriente de la ciudad respectivamente (fig. 4).

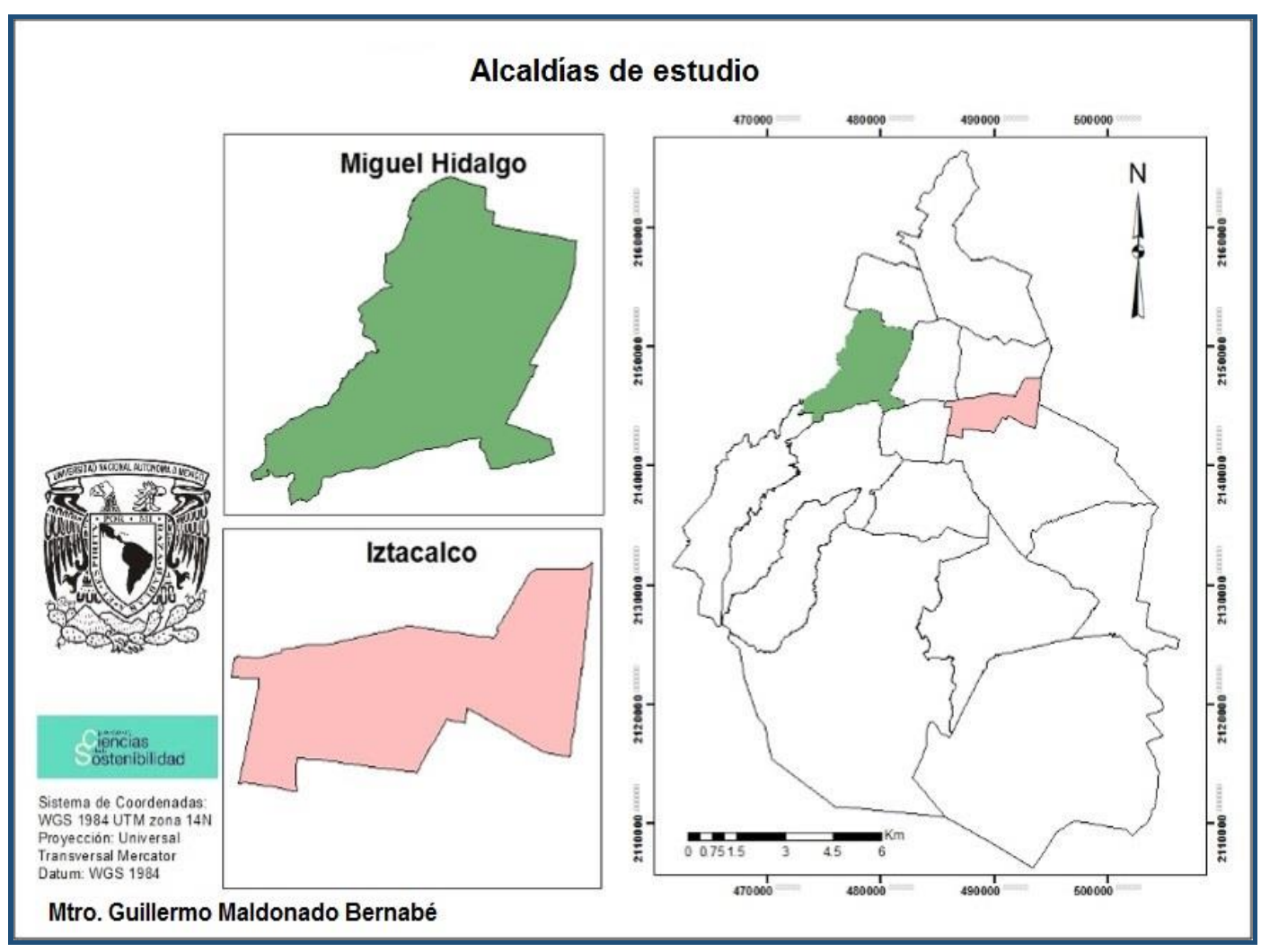

Fig. 3. Ciudad de México y alcaldías de estudio.

Elaboración propia. 
Actualmente, la AMH ocupa el territorio donde se asentaron los pueblos de Tacuba, Tacubaya y Chapultepec que eran tres de los de mayor jerarquía en la época prehispánica. En esta zona corrían ríos que permitieron la construcción de acueductos y molinos, por lo que fue ocupada como asentamiento de reyes durante la época prehispánica y durante la colonización. Posteriormente, durante el mandato de Porfirio Díaz Ordaz, comenzó la urbanización a partir de la construcción del tranvía y la creación de colonias residenciales como San Rafael y Nueva Santa María (Secretaría de Desarrollo Urbano y Vivienda, 2008a).

La AMH se posicionó como una zona de fuertes ingresos económicos, en donde se concentran zonas habitacionales y comerciales, además de áreas de valor ambiental como el bosque de Chapultepec (Secretaría de Desarrollo Urbano y Vivienda, 2008a), también cuenta con el parque Bicentenario inaugurado en 2011. Por otra parte cuenta con inmuebles de importancia nacional como es el Observatorio de la Ciudad de México, el Conservatorio Nacional de Música, el Auditorio Nacional, la Universidad del Ejército y la Fuerza aérea entre otros (ONUHabitat, 2016). Por otra parte, la AMH es un territorio con un nivel socioeconómico mayor al promedio de la ciudad, ya que la mayoría de sus AGEBS (Área Geoestadística Básica) las cataloga como de muy baja pobreza (Fernández-álvarez, 2017).

Por otra parte la AIZ tiene su origen en una zona agrícola que abastecía a la ciudad de Tenochtitlan en la época prehispánica, ya que era un área sometida al imperio Mexica (Rivera, 2002). El territorio de la alcaldía quedó establecido cuando en 1929 se decretó la división del entonces Distrito Federal en 13 delegaciones, ya que anteriormente este territorio formaba parte de Tlalpan, Iztapalapa e incluso de algunos municipios del estado de México. El desarrollo de la AIZ se dio a partir de colonias populares y asentamientos irregulares, además de que en un principio se entremezclaron zonas industriales y unidades habitacionales (Secretaría de Desarrollo Urbano y Vivienda, 2008b).

Esta situación generó problemas en el abastecimiento de los servicios, además de escasa planeación del territorio, lo que ha repercutido en la falta de espacios públicos y áreas verdes. Sin embargo, en el territorio de esta alcaldía se conservan templos y monumentos de valor histórico como el ex convento de San Matías, la Capilla de la Santa Cruz, el templo de Santa Anita además de inmuebles como el Palacio de los Deportes, la Ciudad Deportiva, el Autódromo Hermanos Rodríguez, la Unidad Profesional Interdisciplinaria de Ingeniería y Ciencias sociales y Administrativas (Secretaría de Desarrollo Urbano y Vivienda, 2008b). En el caso de la Alcaldía Iztapalapa Fernández-Álvarez (2017), la clasifica como un territorio de pobreza media.

A pesar de los distintos procesos de urbanización y composición del territorio de ambas alcaldías, los recursos económicos destinados a ellas es similar (fig. 5), lo que en teoría es benéfico para la AIZ, ya que de esta manera cuenta con los ingresos suficientes para atender las necesidades de su población y apostar por alcanzar un desarrollo similar al de la DMH.

Sin embargo, esta similitud en los presupuestos no se puede interpretar, directamente, con igualdad en la inversión en obras públicas, programas sociales y mantenimiento de áreas verdes ya que las prioridades y condiciones sociales de cada alcaldía son distintas. Como ejemplo se puede mencionar la población de cada una ya que, históricamente, la AIZ siempre ha concentrado mayor población que la $\mathrm{AMH}$, aún con el descenso poblacional que se dio en ambas entre 1990 y 2015 (fig. 6). En la encuesta intercensal de 2015 (Instituto Nacional de Estadística Geografía e Informática, 2015b), la AIZ presentó un aumento de población por lo que puede estar pasando por un proceso de repoblación, sin embargo esta tendencia no puede ser asegurado con los datos actuales. 
Tabla 2. Presupuesto total destinado a las alcaldías. Fuente: Diario Oficial de la Federación 1990, Gaceta Oficial del Distrito Federal, 1999, 2009, 2014.

\begin{tabular}{|l|c|c|c|c|}
\hline \multicolumn{1}{|c|}{ Alcaldía } & \multicolumn{4}{c|}{ Presupuesto (\%) } \\
\hline & $\mathbf{1 9 9 0}$ & $\mathbf{2 0 0 2}$ & $\mathbf{2 0 1 0}$ & $\mathbf{2 0 1 5}$ \\
\hline Álvaro Obregón & 7 & 7 & 7 & 7 \\
\hline Azcapotzalco & 5 & 5 & 5 & 5 \\
\hline Coyoacán & 8 & 6 & 6 & 6 \\
\hline Cuajimalpa & 5 & 3 & 3 & 4 \\
\hline Gustavo A. Madero & 11 & 12 & 12 & 11 \\
\hline Iztacalco & 3 & 5 & 5 & 5 \\
\hline Iztapalapa & 11 & 14 & 13 & 13 \\
\hline Magdalena Contreras & 3 & 3 & 3 & 3 \\
\hline Milpa Alta & 3 & 3 & 3 & 3 \\
\hline Tláhuac & 3 & 4 & 4 & 4 \\
\hline Tlalpan & 5 & 6 & 6 & 6 \\
\hline Xlaborachimilco & 7 & 5 & 5 & 6 \\
\hline Benito Juárez & 5 & 5 & 5 & 5 \\
\hline Cuauhtémoc & 10 & 9 & 10 & 9 \\
\hline Miguel Hidalgo & 7 & 6 & 6 & 6 \\
\hline Venustiano Carranza & 7 & 7 & 7 & 7 \\
\hline
\end{tabular}

Elaboración propia.

Tabla 3. Comparación de la población en ambas alcaldías, Fuente: Instituto Nacional de Estadística Geografía e Informática, 1997, 2000, 2011, 2015a.

\begin{tabular}{|l|c|c|c|c|c|}
\hline & $\begin{array}{c}\text { Habitantes } \\
\mathbf{1 9 9 0}\end{array}$ & $\begin{array}{c}\text { Habitantes } \\
\mathbf{2 0 0 0}\end{array}$ & $\begin{array}{c}\text { Habitantes } \\
\mathbf{2 0 1 0}\end{array}$ & $\begin{array}{c}\text { Habitantes } \\
\mathbf{2 0 1 5}\end{array}$ & $\begin{array}{c}\text { Tasa de crecimiento } \\
\text { (1990-2015) }\end{array}$ \\
\hline Miguel Hidalgo & 406,868 & 352,640 & 372,889 & 364,439 & -0.439 \\
\hline Iztacalco & 448,322 & 411,321 & 384,326 & 390,348 & -0.551 \\
\hline $\begin{array}{l}\text { Ciudad de } \\
\text { México }\end{array}$ & $8,235,774$ & $8,605,239$ & $8,851,080$ & $8,918,653$ & 0.319 \\
\hline
\end{tabular}

Elaboración propia.

Aunque la densidad poblacional es de más del doble en la AIZ (1.69 personas por cada $100 \mathrm{~m}^{2}$ ) que en la DMH $\left(0.77\right.$ personas por cada $\left.100 \mathrm{~m}^{2}\right)$, las condiciones de vida de la población en ambos territorios, aunque distintas, se equilibraron. Lo anterior si se considera la cobertura de servicios y las características de la vivienda, en cuanto a los materiales de construcción (fig. 7). 
Tabla 4. Características de las viviendas en las alcaldías. Instituto Nacional de Estadística Geografía e Informática, $1997,2015 b$.

\begin{tabular}{|l|c|c|c|c|}
\hline & \multicolumn{2}{|c|}{ Miguel Hidalgo } & \multicolumn{2}{c|}{ Iztacalco } \\
\hline & $\mathbf{1 9 9 0}$ & $\mathbf{2 0 1 5}$ & $\mathbf{1 9 9 0}$ & $\mathbf{2 0 1 5}$ \\
\hline Total de viviendas & 98,051 & 128,042 & 93,816 & 110,174 \\
\hline Piso de tierra & $0.24 \%$ & $0.03 \%$ & $0.92 \%$ & $0.10 \%$ \\
\hline $\begin{array}{l}\text { Piso de madera, mosaico u } \\
\text { otro }\end{array}$ & $58 \%$ & $89 \%$ & $40 \%$ & $74 \%$ \\
\hline Pared de cartón & $0.11 \%$ & $0.08 \%$ & $0.53 \%$ & $0.03 \%$ \\
\hline Pared de tabique & $94 \%$ & $99 \%$ & $96 \%$ & $98 \%$ \\
\hline Techo de cartón & $3.2 \%$ & $0.6 \%$ & $6 \%$ & $0.21 \%$ \\
\hline Techo de losa & $85 \%$ & $96 \%$ & $78 \%$ & $95 \%$ \\
\hline
\end{tabular}

Elaboración propia.

En la figura anterior se muestra que es prácticamente nula la existencia de viviendas con piso de tierra, pared y techos de cartón, mientras que el acceso a servicios como agua potable, electricidad, gas (contenedor y entubado) y drenaje básicos fue superior al 98\%, en 2015 (figura 8), lo que representa un avance importante en la calidad de la vivienda y acceso a servicios con respecto al año 1990.

Tabla 5. Cobertura de servicios por viviendas de las alcaldías. Instituto Nacional de Estadística Geografía e Informática, 1997, 2015b 2015 *SD: Sin datos.

\begin{tabular}{|c|c|c|c|c|}
\hline Acceso a servicios & \multicolumn{2}{|c|}{ Miguel Hidalgo } & \multicolumn{2}{c|}{ Iztacalco } \\
\hline & $\mathbf{1 9 9 0}$ & $\mathbf{2 0 1 5}$ & $\mathbf{1 9 9 0}$ & $\mathbf{2 0 1 5}$ \\
\hline Electricidad & $99 \%$ & $100 \%$ & $99 \%$ & $100 \%$ \\
\hline Agua potable & $99 \%$ & $100 \%$ & $74 \%$ & $99 \%$ \\
\hline Drenaje & $83 \%$ & $99 \%$ & $97 \%$ & $98 \%$ \\
\hline Gas & SD* & $98 \%$ & SD $^{*}$ & $98 \%$ \\
\hline
\end{tabular}

Elaboración propia

Por otra parte, las características laborales no reflejan grandes diferencias en cuanto a población ocupada ni el campo laboral, ya que la mayoría de la población en ambas alcaldías se desempeña en el sector terciario (fig. 9).

Si se considera que las características analizadas han pasado de grado de desigualdad alto a uno bajo, se puede interpretar que las alcaldías, a pesar de sus distintos orígenes, están comenzando a pasar por un proceso de homogenización en cuanto a las condiciones de vida de sus habitantes, sin embargo, este proceso no se ve reflejado en la configuración del territorio de ellas. 
Tabla 6. Actividades económicas desagregadas. Cálculos con base en Instituto Nacional de Estadística Geografía e Informática, 1997, 2015b.

\begin{tabular}{|l|c|c|c|c|c|c|}
\hline & \multicolumn{2}{|c|}{ Miguel Hidalgo } & \multicolumn{2}{c|}{ Iztacalco } & \multicolumn{2}{c|}{ Ciudad de México } \\
\hline & 1990 & 2015 & 1990 & 2015 & 1990 & 2015 \\
\hline Población de 15+ años & 301,209 & 305,043 & 314,656 & 315,498 & $6,217,435$ & $7,128,836$ \\
\hline $\begin{array}{l}\text { Población económicamente } \\
\text { activa }\end{array}$ & $54 \%$ & $63 \%$ & $51 \%$ & $58 \%$ & $47 \%$ & $58 \%$ \\
\hline Población ocupada & $98 \%$ & $97 \%$ & $97 \%$ & $95 \%$ & $97 \%$ & $95 \%$ \\
\hline sector primario & Sin datos & $0.09 \%$ & Sin datos & $0.18 \%$ & Sin Datos & $0.49 \%$ \\
\hline sector secundario & $23 \%$ & $11.06 \%$ & $27 \%$ & $13.72 \%$ & $2.69 \%$ & $14.86 \%$ \\
\hline sector terciario & $71 \%$ & $68.65 \%$ & $69 \%$ & $62.03 \%$ & $68 \%$ & $61.57 \%$ \\
\hline
\end{tabular}

Elaboración propia.

En general, la población de la CDMX disfruta de buena calidad de vida ya que es una de las entidades con menor pobreza y rezago social. En este sentido las alcaldías de estudio siguen una tendencia similar ya que tanto la AMH como la AIZ se encuentran catalogadas como unidades político-administrativas con bajo número de población en situación de pobreza y rezago social (Consejo Nacional de Evaluación de la Politica de Desarrollo Social, 2013).

\section{RESUltados y DiscusióN}

Los resultados muestran que las AVU de ambas alcaldías presentan grandes diferencias, en la AMH estos espacios ocupan cerca del 19\% del territorio, mientras que en la AIZ la superficie es aproximadamente $10 \%$ del territorio. Este porcentaje representa una gran superficie, como se puede ver en la tabla 7, la AMH tiene más del triple de AVU que la AIZ.

Por otra parte, si se comparan los resultados de estudios anteriores de AVU en la CDMX hay diferencias notables entre ellos, principalmente por los criterios de evaluación de cada uno, a pesar de ello existe un punto en común, y es que todos reflejan diferencias considerables entre las alcaldías, siempre con mayoría de AVU para la $\mathrm{AMH}$, por lo que este fenómeno no ha pasado desapercibido y sin embargo las acciones tomadas para abordar esta problemática resultan inefectivas (Tabla 7).

Tabla 7. Comparativo de la superficie de AVU en las alcaldías Miguel Hidalgo e Iztacalco con estudios previos: Procuraduria Ambiental y de Ordenamiento Territorial, 2010; Secretaría del Medio Ambiente, 2003.

\begin{tabular}{|c|c|c|c|}
\hline & $\begin{array}{c}\text { Secretaría del Medio Ambiente, } \\
\mathbf{2 0 0 3}\end{array}$ & PAOT, 2010 & Datos propios \\
\hline Miguel Hidalgo & $8,890,000 \mathrm{~m}^{2}$ & $14,673,613 \mathrm{~m}^{2}$ & $9,109,625 \mathrm{~m}^{2}$ \\
\hline Iztacalco & $2,500,000$ & $2,885,196 \mathrm{~m}^{2}$ & $2,400,746 \mathrm{~m}^{2}$ \\
\hline
\end{tabular}


Estas grandes diferencias en la superficie ocupada por AVU en cada territorio pueden tener consecuencias para el desarrollo social de la población. La existencia de menos AVU en la AIZ se agrava si se considera que esta alcaldía tiene un territorio menor, y sin embargo concentra mayor población que la DMH, en este sentido las AVU no son suficientes para proporcionar los servicios ambientales necesarios a la población. La insuficiencia de AVU puede tener consecuencias como aumento de inseguridad, enfermedades y estrés en la población, sin mencionar las que existen menores de recreación dentro del territorio.

En este caso, actualmente no hay grandes diferencias socioeconómicas, sin embargo, el origen y desarrollo de ambas alcaldías fue distinto, por lo que esta historia urbanística particular si está teniendo consecuencias en la cantidad de AVU en estos territorios.

Los siguientes mapas muestran las áreas verdes de ambas alcaldías, es importante resaltar que hay espacios principales en ellas, por una parte, en la AMH existe el bosque de Chapultepec, que con sus $6.7 \mathrm{~km}^{2}$ es el área verde más grande de la alcaldía y de la ciudad (Secretaría de Desarrollo Urbano y Vivienda, 2008a). Este espacio aporta la mayor parte del AVU de la alcaldía y provee grandes beneficios a su población. Por otra parte, en la AMH se creó recientemente (2011) el parque bicentenario con lo que se aumentó la superficie de área verde de la alcaldía.

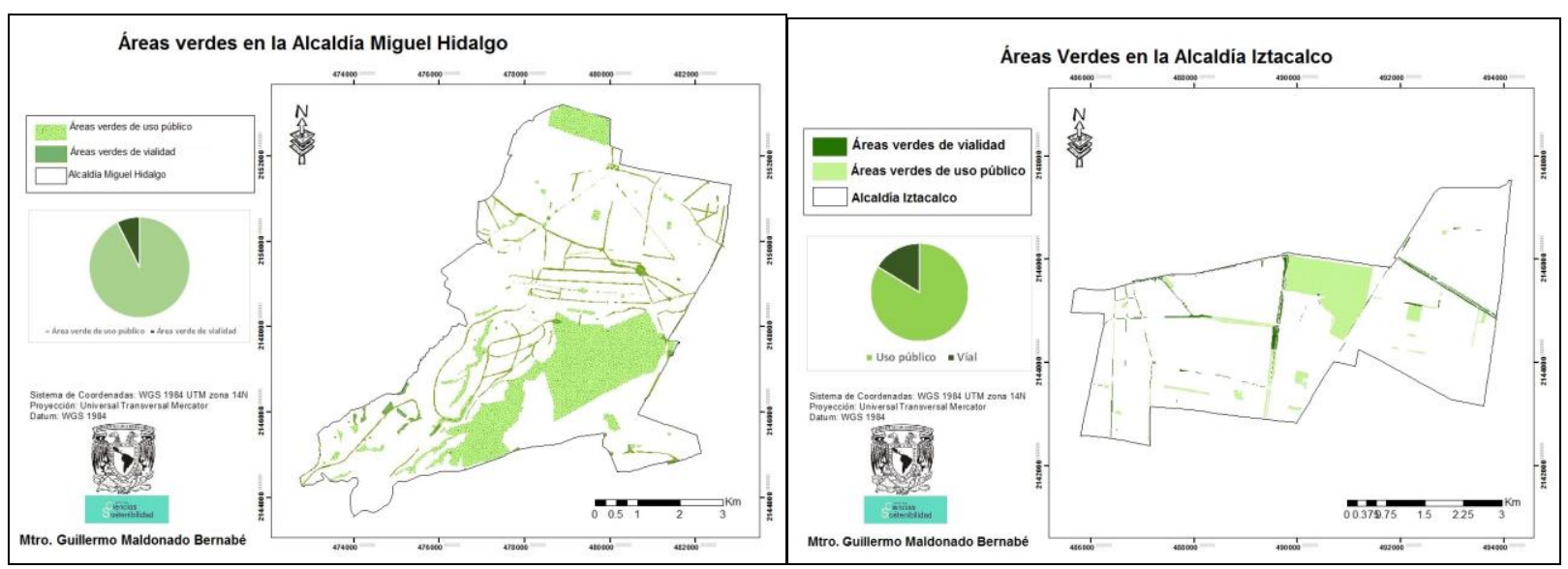

Fig. 4. Áreas verdes en las alcaldías Miguel Hidalgo e Iztacalco.

Elaboración propia.

Por otra parte, la AIZ tiene como AVU representativa a La Ciudad Deportiva con 920, $000 \mathrm{~m}^{2}$ de extensión, esto es considerablemente menor que el bosque de Chapultepec, es por ello que se puede afirmar que la población de la AIZ no se beneficia de la misma manera de los servicios ambientales de los parques y AVU de la ciudad.

En una comparativa nacional, la AMH tiene mayor superficie de áreas verdes que la Ciudad de Monterrey en todo su territorio, lo mismo sucede en el caso de Mérida y Toluca. Es importante mencionar que esta comparación se hace entre territorios distintos, por una parte, la AMH y la AIZ son parte de una ciudad, mientras que Monterrey es una ciudad completa. Sin embargo, estos resultados son significativos ya que demuestran que la falta de áreas verdes es un problema general en el país, además de que evidencia que la AMH es uno de los territorios con mayor superficie de AVU en México (fig. 12). 
Tabla 8. Áreas verdes en distintos territorios de México.

\begin{tabular}{|l|c|c|c|c|c|c|}
\hline Ciudad/Municipio & $\begin{array}{c}\text { Superficie } \\
\left(\mathbf{k m}^{2}\right)\end{array}$ & $\begin{array}{c}\text { Superficie de } \\
\text { área verde }\left(\mathbf{m}^{\mathbf{2}}\right)\end{array}$ & $\begin{array}{c}\text { Relación con } \\
\text { el territorio }\end{array}$ & Habitantes & $\begin{array}{c}\text { AV/H } \\
\left(\mathbf{m}^{\mathbf{2}}\right)\end{array}$ & Autor \\
\hline $\begin{array}{l}\text { Alcaldía Miguel } \\
\text { Hidalgo }\end{array}$ & 47 & $9,109,625$ & $19.23 \%$ & 364,439 & 25 & Datos propios \\
\hline $\begin{array}{l}\text { Ciudad de } \\
\text { Monterrey }\end{array}$ & 969 & $7,042,400$ & $0.7 \%$ & $1,135,000$ & 6 & $\begin{array}{c}\text { Jiménez, Cuéllar, y } \\
\text { Treviño, 2013 }\end{array}$ \\
\hline Mérida, Yucatán & 209 & $5,120,925$ & $2.45 \%$ & 830,732 & 6 & $\begin{array}{c}\text { Pérez-Medina y } \\
\text { López-Falfán, 2015 }\end{array}$ \\
\hline Valle de Toluca & 452 & $4,097,805$ & $0.9 \%$ & 819,561 & 5 & $\begin{array}{c}\text { Galindo-Bianconi y } \\
\text { Victoria-Uribe, 2012 }\end{array}$ \\
\hline Alcaldía Iztacalco & 23 & $2,400,716$ & $10.43 \%$ & 390,348 & 6 & Datos propios \\
\hline $\begin{array}{l}\text { Ciudad de } \\
\text { Durango }\end{array}$ & 10 & $1,178,307$ & $11.78 \%$ & 468,468 & 2 & $\begin{array}{c}\text { Municipio de } \\
\text { Durango, 2006 }\end{array}$ \\
\hline
\end{tabular}

Elaboración propia.

Por otra parte, tanto la AMH como la AIZ tienen menor territorio y población que el resto de las ciudades en la figura 12, esto repercute en la manera en que la población se beneficia de las AVU, ya que en la AMH el índice de $\mathrm{AV} / \mathrm{H}$ es de $25 \mathrm{~m}^{2}$, mientras que el resto de los ejemplos apenas rebasa los $6 \mathrm{~m}^{2}$. Si se considera que el mínimo de área verde recomendable por habitante es de entre $9 \mathrm{~m}^{2}$ (Hinojosa, 2014; Reyes y Figueroa, 2010; Sorensen, Barzetti, y Williams, 1998), y $20 \mathrm{~m}^{2}$ (Handley, 2003), solo la AMH cumple con este criterio.

Es claro que en este caso se comparan territorios distintos (municipios y ciudades) por lo que si se consideran ya sea toda la Ciudad de México o solamente los espacios con mayor cantidad de áreas verdes de las ciudades consideradas, los resultados cambiarían. Sin embargo, al no existir estudios que señalen con precisión estos datos, se hicieron estas comparativas para dimensionar que tan bien o mal están los territorios seleccionados en cuanto a AVU.

Haciendo el mismo ejercicio en el contexto internacional, la AMH puede compararse con ciudades como Londres e incluso se sitúa por encima de Berlín y Leipzig en cuanto a la relación $\mathrm{AV} / \mathrm{H}$, es decir que esta alcaldía está muy bien posicionada en cuanto a cobertura de AVU se refiere (fig. 13).

Las comparaciones anteriores reflejan las diferencias existentes entre las AVU de cada alcaldía, ya que tanto nacional como internacionalmente ambas se encuentran en distintas situaciones. Estos resultados son ejemplos de los contrastes que generan la planeación de un territorio $(\mathrm{AMH})$ y la urbanización desorganizada de otro (AIZ) aun cuando se encuentran en la misma ciudad y tienen un tiempo de desarrollo similar.

Los resultados anteriores hacen referencia al total de AVU, es decir de ambas categorías (uso público y vial), sin embargo, a continuación, se presenta el análisis de las categorías de manera individual. 
Tabla 9. Comparación con ciudades internacionales.

\begin{tabular}{|l|c|c|}
\hline \multicolumn{1}{|c|}{ Ciudad } & AV/H $\left(\mathbf{m}^{\mathbf{2}}\right)$ & Autor \\
\hline Pekín* & 44 & Hinojosa, 2014 \\
\hline Londres & 27 & Cvejić et al., 2015 \\
\hline AMH & 25 & Datos propios \\
\hline Leipzig & 10 & Berlin.de, n.d. \\
\hline $\begin{array}{l}\text { Santiago de } \\
\text { Chile }\end{array}$ & 2.4 & Reyes Päcke y Figueroa Aldunce, 2010 \\
\hline Málaga, España & 7.6 & Observatorio de Medio Ambiente Urbano, 2015 \\
\hline Berlín & 6 & Berlin.de, n.d. \\
\hline
\end{tabular}

Elaboración propia.

\section{Áreas verdes de uso público de la Alcaldía Miguel Hidalgo e Iztacalco}

Los siguientes mapas (fig. 14) muestran los espacios considerados como área verde de uso público (AVUP) en cada alcaldía, en donde nuevamente se encontraron diferencias notables en cuanto al número y superficie de estos espacios.

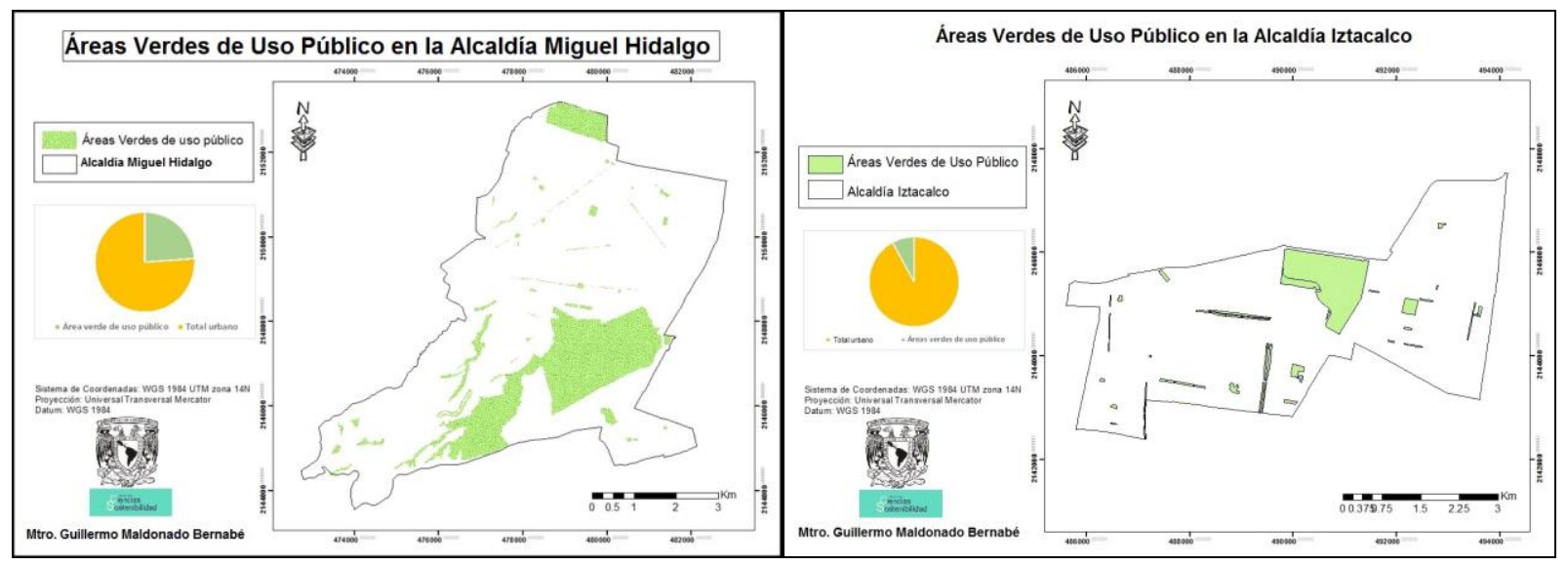

Fig. 5. Áreas verdes de uso público de las alcaldías de estudio.

Elaboración propia.

De acuerdo con los resultados, en la AMH existen cerca del doble de AVUP en comparación con la AIZ, sin embargo, la superficie que ocupan es aproximadamente cuatro veces mayor. Esto significa que en la AMH estos espacios son más abundantes y de mayor tamaño que en la AIZ (fig. 15). 
Tabla 10. Áreas verdes y superficie total por alcaldía.

\begin{tabular}{|c|c|c|}
\hline Alcaldía & Total de AVM & Superficie de AVU $\left(\mathbf{m}^{2}\right)$ \\
\hline Miguel Hidalgo & 108 & $8,440,450$ \\
\hline Iztacalco & 52 & $2,011,247$ \\
\hline
\end{tabular}

Elaboración propia.

Lo anterior provoca dos realidades para las alcaldías de estudio, ya que la existencia de más AVUP en la AMH genera, para la población de esta alcaldía, mayores oportunidades de recreación, convivencia y cohesión social (Atiqul Haq, 2011; Jennings, Larson, y Yun, 2016; Maas, Van Dillen, Vertheij, y Groenewegen, 2009; Sherer, 2003). Esto reduce el riesgo de padecer problemas de salud como ansiedad, depresión, obesidad e incluso diabetes ya que estos espacios se utilizan para realizar ejercicio y otro tipo de actividades al aire libre (Atiqul Haq, 2011; Jennings et al., 2016; Kendal et al., 2016; World Health Orgaization, 2016).

Por otra parte, el comportamiento social en la AIZ puede afectarse debido a la falta de AVUP ya que diversos estudios señalan que las personas que viven en lugares con menos vegetación a $1 \mathrm{~km}$ de sus casas, se sienten solas y son menos sociales (Maas et al., 2009), por el contrario las personas que habitan cerca de AVUP $(800 \mathrm{~m})$ muestran mayor facilidad para socializar (Fan, Das, y Chen, 2011).

Por lo anterior existen distintas recomendaciones del ideal de AVUP que una ciudad debe tener por habitante, en el caso latinoamericano se menciona que deben haber aproximadamente $9 \mathrm{~m}^{2}$ de por habitante (Hinojosa, 2014; Reyes y Figueroa, 2010; Sorensen et al., 1998), en el caso Europeo, se hace mención de que debe haber $20 \mathrm{~m}^{2} / \mathrm{H}$ (Handley, 2003). En este sentido, las alcaldías de estudio tienen resultados contrastantes ya que en general, la AIZ no ha superado los $5 \mathrm{~m}^{2} / \mathrm{H}$ desde 1990 , mientras que en la AMH desde esa fecha ya había más de $20 \mathrm{~m}^{2} / \mathrm{H}$. En ambos casos este promedio aumentó desde 1990, sin embargo, la diferencia entre ellas se mantiene (fig. 16).

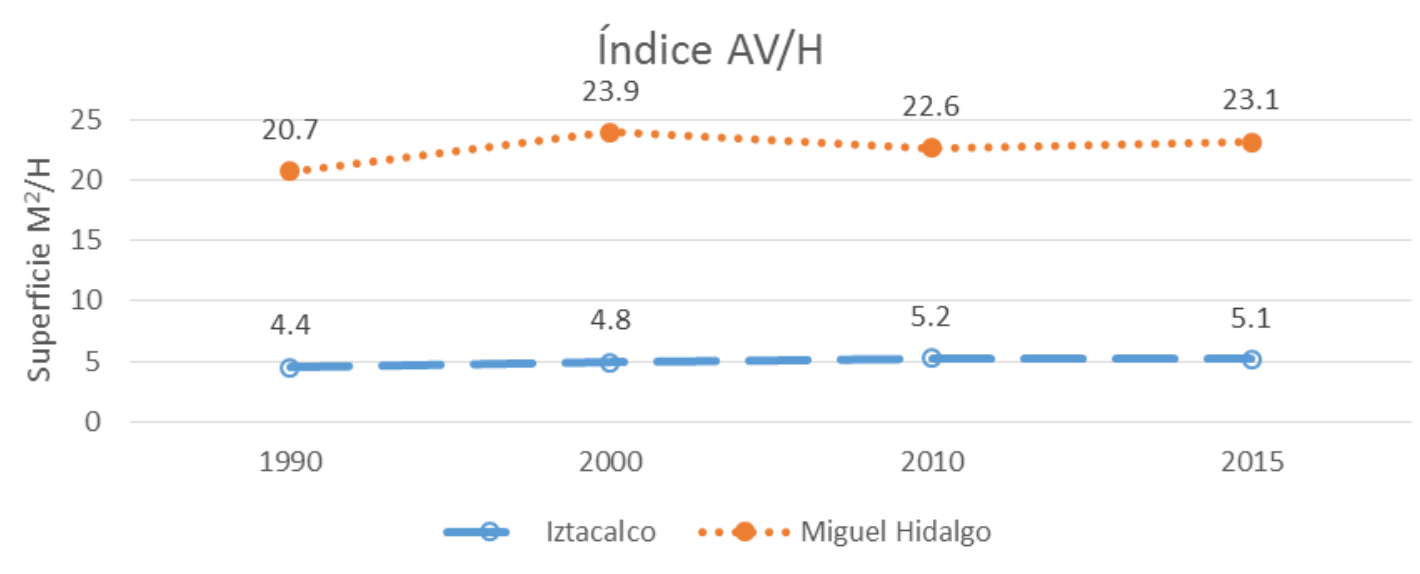

Gráfica 1. Relación AV/H considerando la categoría de Área verde con mobiliario. Elaboración propia. 
Estos resultados señalan una necesidad de intervenir en el territorio de la AIZ para implementar programas de recuperación de espacios públicos y creación de algunos nuevos. Como ya se mencionó, existen planes y programas puestos en marcha, sin embargo, los análisis muestran que, por lo menos hasta 2015, estos no fueron suficientes para mejorar la situación de la AIZ.

El análisis de AVUP incluye áreas sin cobertura vegetal como son: kioscos, estacionamientos, caminos y otro tipo de estructuras necesarias para su uso, por lo que este cálculo no refleja la superficie real de vegetación en estos espacios. Por ello se utilizó el NDVI para evaluar de qué manera cambió la vegetación en las fechas de estudio. En la siguiente sección se presentan los resultados.

\section{Vegetación de las áreas verdes urbanas}

Tomando en cuenta el total de superficie ocupada por las AVUP (8, 440, $450 \mathrm{~m}^{2}$ en la AMH y 2, 011, $247 \mathrm{~m}^{2}$ para la AIZ) se calculó la superficie de cobertura vegetal al interior de estas zonas, a través de un análisis de vegetación (NDVI) mediante el software Qgis. De esta manera se calcularon los cambios en la cobertura vegetal de estos espacios.

Los siguientes mapas (figs. 17 y 18) muestran los 108 espacios categorizados como "áreas verdes de uso público" de la AMH en las fechas de estudio. En ellos se muestra las zonas con vegetación y las zonas sin vegetación en color verde y amarillo respectivamente.

Al igual que en la DMH, los mapas de las figuras 19 y 20 muestran los cambios en la superficie verde al interior de los 52 espacios contabilizados en la DI.

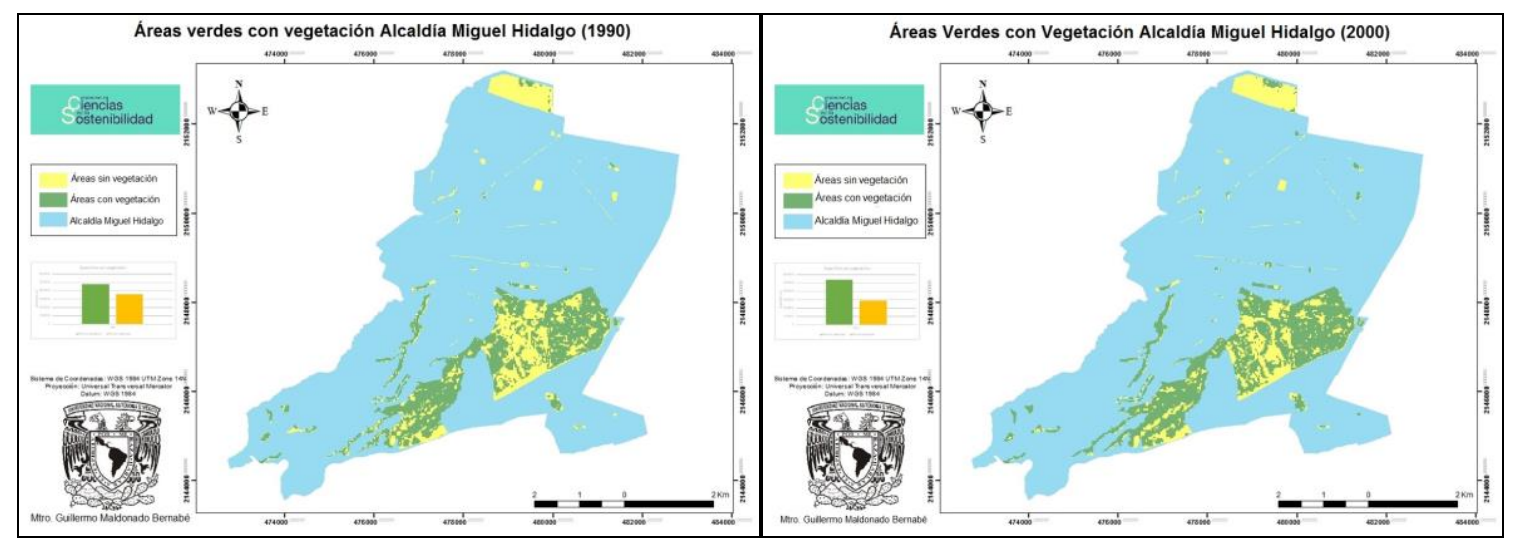

Fig. 6. Cobertura vegetal de Miguel Hidalgo 1990 y 2000.

Elaboración propia. 

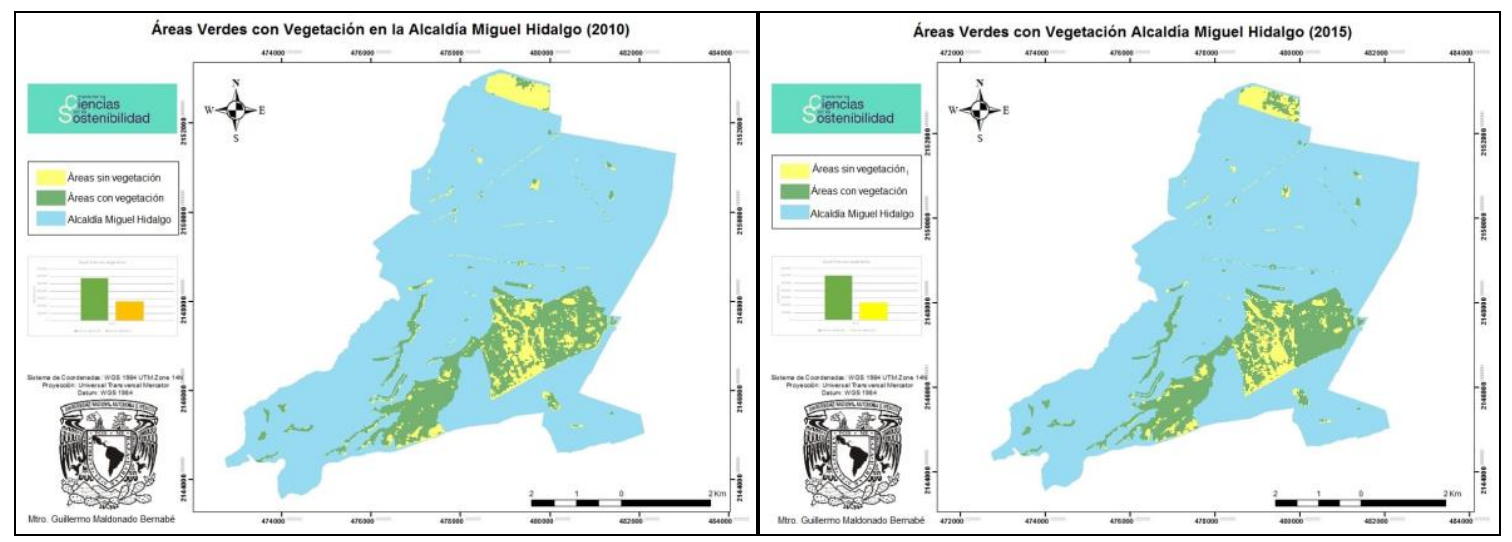

Fig. 7. Cobertura vegetal de Miguel Hidalgo, 2010 y 2015. Elaboración propia.

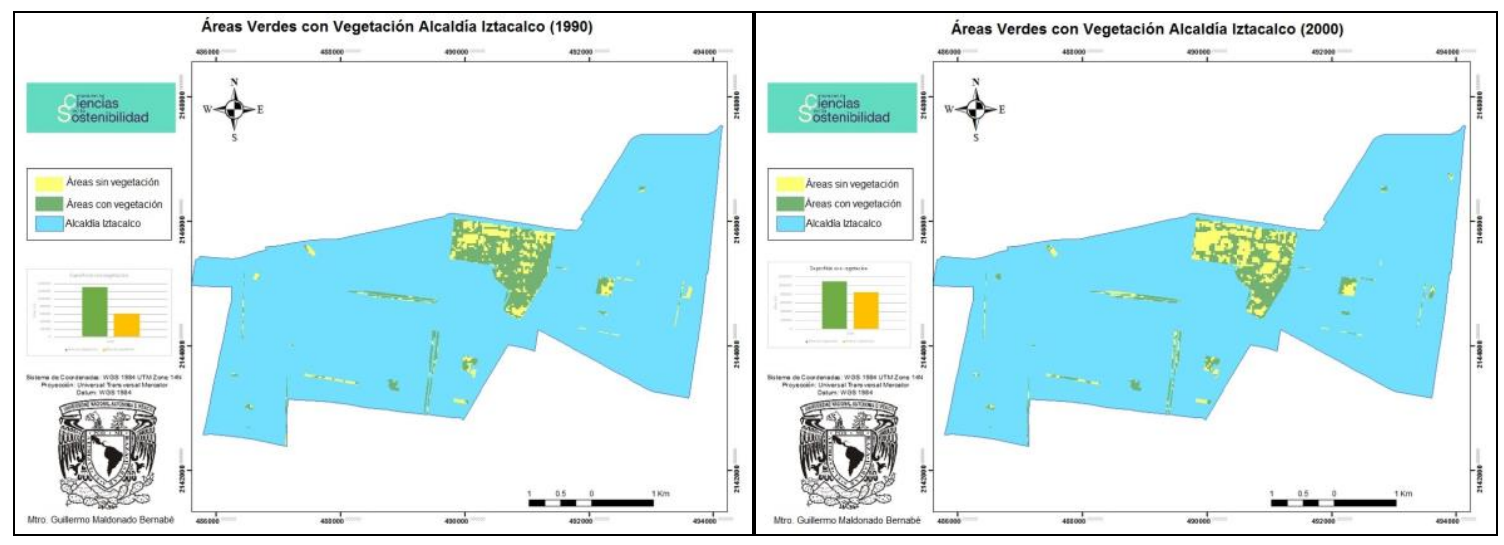

Fig. 8. Cobertura vegetal de Iztacalco 1990 y 2000.

Elaboración propia.

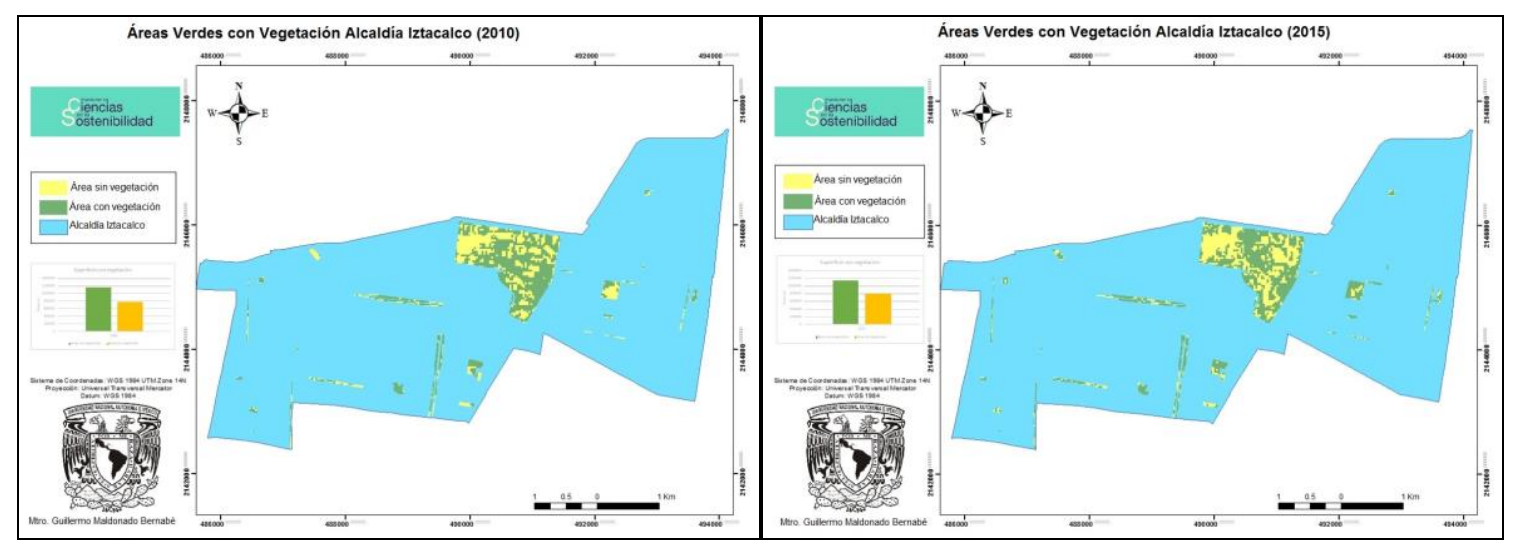

Fig. 9. Cobertura vegetal de Iztacalco, 2010 y 2015.

Elaboración propia 
De acuerdo con los resultados de la vegetación de las AVUP en la AMH, existe una constante mejoría ya que desde 1990 a 2015 se ganó $1,288,245 \mathrm{~m}^{2}$ de cobertura vegetal, por el contrario, en la AIZ la cobertura vegetal tiene altibajos en los años de estudio, sin embargo, el balance final resulta en perdida de cobertura de 172,361 $\mathrm{m}^{2}$ (figura 21). La variación de la vegetación en las alcaldías se puede atribuir a los planes de manejo y cuidado a sus áreas verdes, ya que las imágenes con las que se realizó el análisis son de las mismas fechas, por lo que si la afectación fuera debida a las condiciones del clima ambas zonas deberían verse afectadas.

Tabla 11. Cobertura vegetal por año de estudio.

\begin{tabular}{|c|c|c|c|c|c|}
\hline Alcaldía & $\mathbf{1 9 9 0}$ & $\mathbf{2 0 0 0}$ & $\mathbf{2 0 1 0}$ & $\mathbf{2 0 1 6}$ & $\begin{array}{c}\text { Diferencia } \\
(\mathbf{1 9 9 0 - 2 0 1 5})\end{array}$ \\
\hline Miguel Hidalgo & $4,711,204$ & $5,398,979$ & $5,750,953$ & $5,999,449$ & $1,288,245$ \\
\hline Iztacalco & $1,316,472$ & $1,096,950$ & $1,156,659$ & $1,144,110$ & $-172,362$ \\
\hline
\end{tabular}

Elaboración propia.

Esta tendencia negativa muestra que la AIZ perdió cobertura vegetal en las AVUP, lo que reduce la calidad de estos espacios ya que es la vegetación la que provee servicios como retener partículas contaminantes, producir oxígeno, infiltrar agua y reducir las islas de calor entre otros (López, 2013; Salvador, 2003).

Esto muestra que las AVUP no reciben las mismas atenciones por parte de las alcaldías, si se considera que en general el presupuesto de ambas es similar. Es decir, que, a pesar de recibir presupuestos similares, los recursos que se dirigen al mantenimiento de AVUP es distinto. Adicionalmente la falta de AVUP en la DI y el deterioro de su vegetación puede generar costos a las alcaldías por concepto de servicios ambientales no generados (Sherer, 2003). En la siguiente figura se mencionan estimaciones de algunos costos de los servicios ambientales (fig. 22).

Tabla 12. Obtenido de Sherer (2003). Cálculos por árbol con promedio de vida de 50 años.

\begin{tabular}{|l|c|c|}
\hline \multicolumn{1}{|c|}{ Servicio } & Costo (dólares) & Pesos mexicanos (Mayo de 2017) \\
\hline Producción de oxigeno & 31,250 & 562,500 \\
\hline Purificación del aire & 62,000 & $1,116,000$ \\
\hline Infiltración de agua & 37,500 & 675,000 \\
\hline Control de erosión del suelo & 31,250 & 562,500 \\
\hline
\end{tabular}

Elaboración propia.

La valorización económica de los servicios ambientales no fue un objetivo en este estudio, sin embargo, a través de conocer los costos de los servicios ambientales, es posible imaginar los beneficios de áreas verdes con vegetación sana y abundante.

Por supuesto que la vegetación de las áreas de conservación, de banquetas, terrenos baldíos, vialidades y otros espacios también aporta al total de servicios ambientales, sin embargo, el interés de este estudio fue sobre las áreas verdes públicas. A continuación, se presenta el análisis de la vegetación de estos espacios. 


\section{Área Verde de Vialidad}

Los espacios identificados como áreas verdes de vialidad (AVV), en la DMH, ocupan 669, 175 $\mathrm{m}^{2}$, es decir que representan el $1.44 \%$ del total (fig. 23). Es verdad que estos espacios no se consideran áreas recreativas, sin embargo forman parte de la infraestructura verde de la ciudad y cumplen con funciones ambientales, además de embellecer la vista de la ciudad, es decir son espacios multifuncionales (Grant, 2010).

En general, el AVV de la DMH sigue la misma tendencia que el AVUP, es decir que la superficie de cobertura vegetal en ellos aumentó hasta poco más del doble de superficie. Tal como se muestra en la siguiente figura, el aumento total de la vegetación es de 186, $003 \mathrm{~m}^{2}$ (fig. 24).

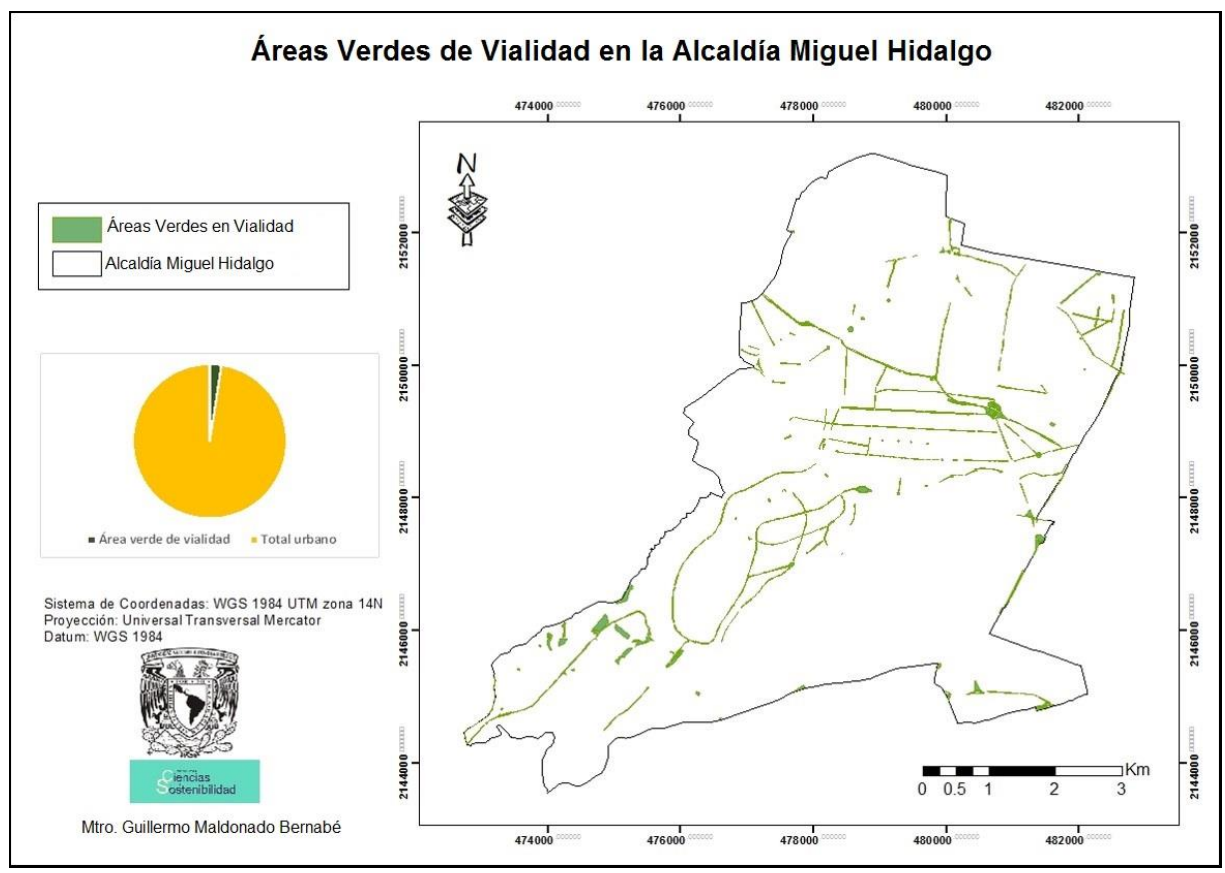

Fig. 10. Áreas verdes de vialidad, Miguel Hidalgo.

Elaboración propia.

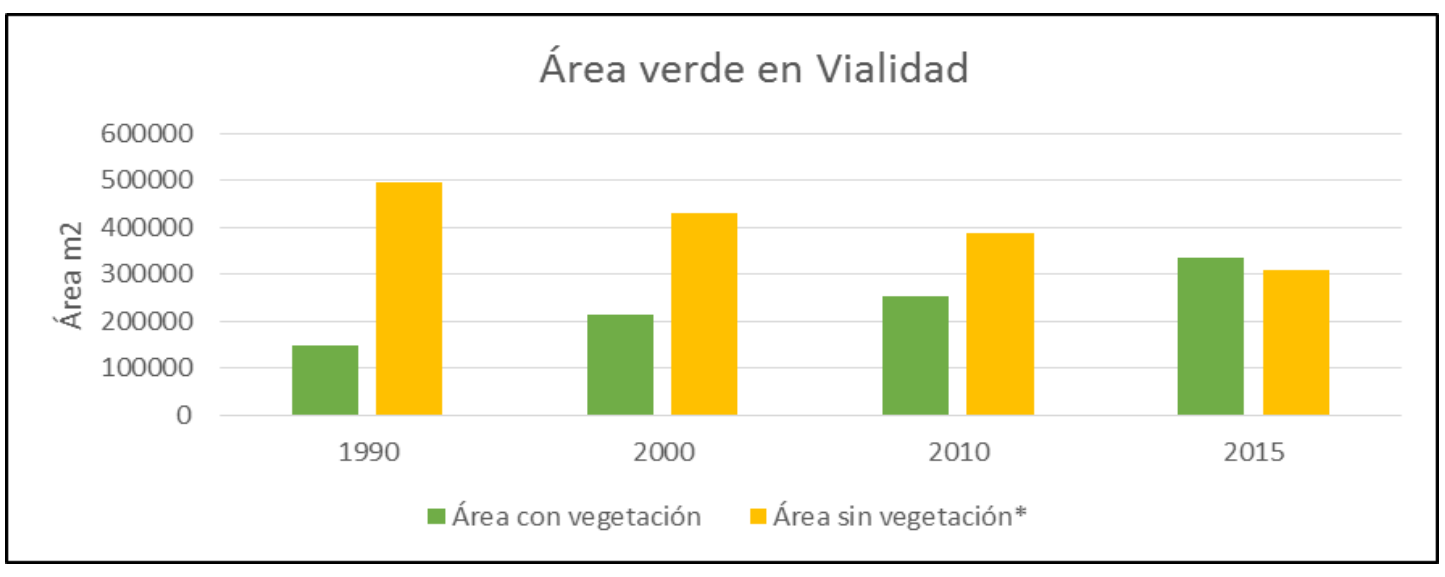

Gráfica 2. Cambio de las áreas verdes de vialidad en Miguel Hidalgo. *Espacio sin cobertura vegetal. Elaboración propia. 
En este caso el programa que está directamente relacionado con la vegetación de la vialidad es el programa de reforestación urbana, cuyo objetivo es sanear y reforestar avenidas y camellones importantes de la ciudad, por lo que se puede decir que al menos en esta ha funcionado. Por su parte en la DI las AVV de la DI corresponden al $1.68 \%$ de su territorio, lo que significa que ocupan 389, $496 \mathrm{~m}^{2}$ del total de la alcaldía. En las AVV la superficie de vegetación aumentó, aunque en menor medida que en la DMH, lo que tiene que ver directamente con que la DI tiene menor cantidad de camellones y glorietas. El siguiente mapa y la gráfica muestran la superficie ocupada por vialidad y los cálculos de la vegetación por año respectivamente (fig. 25).

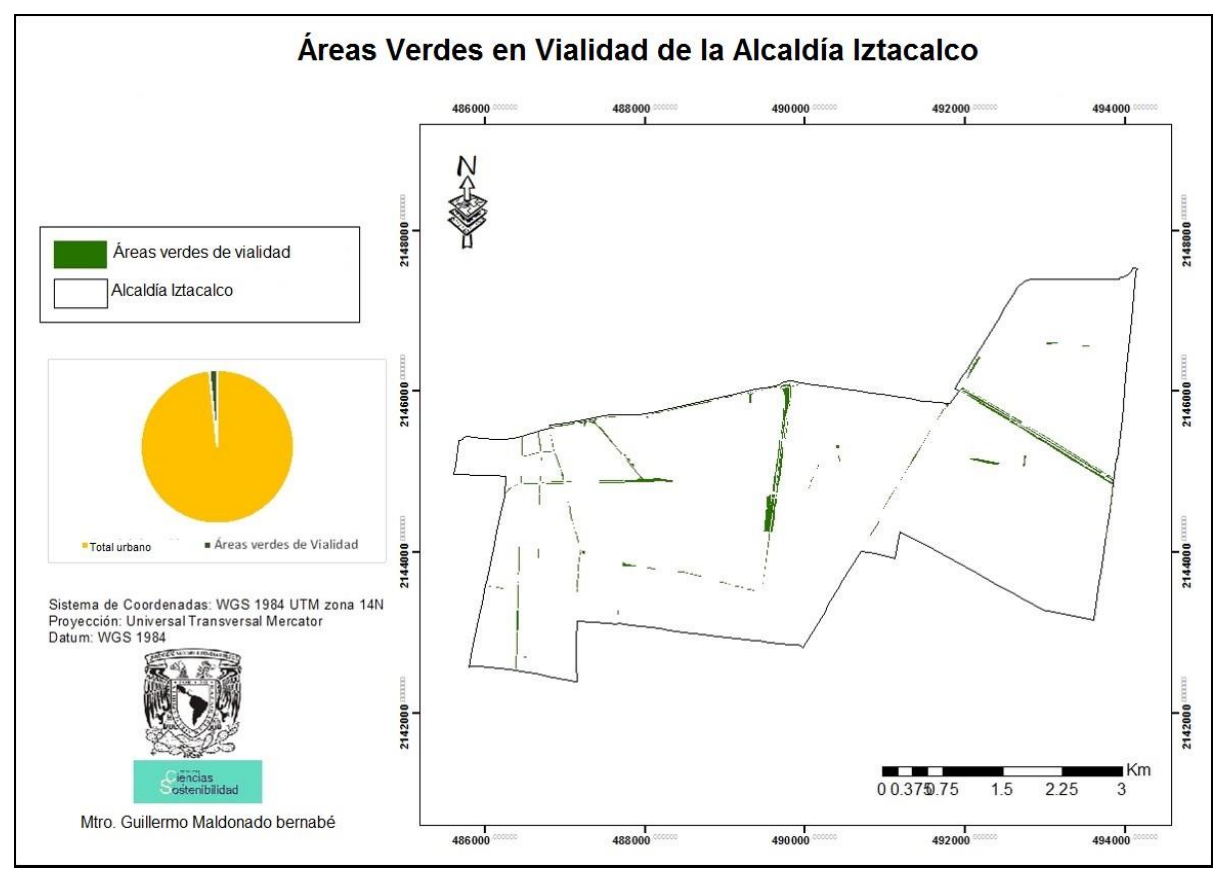

Fig. 11. Área Verde de Vialidad en Iztacalco.

Elaboración propia.

Por lo menos en este criterio el programa de reforestación también funcionó ya que se ganó 15 , $574 \mathrm{~m}^{2}$ de cobertura vegetal (fig. 26).

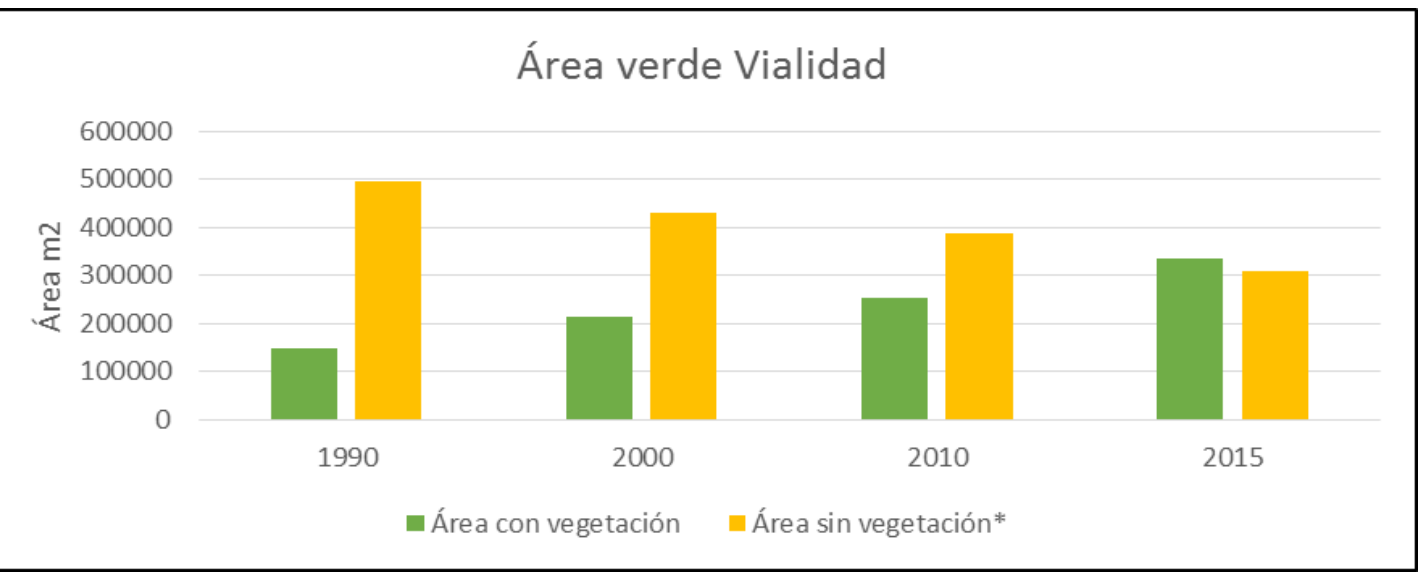

Gráfica 3. Cambio de las áreas verdes de vialidad en Miguel Hidalgo.

Elaboración propia. 


\section{CONCLUSIONES}

De acuerdo con los censos de INEGI e información de CONAPO, en la ciudad de México se han reducido las brechas en cuando a la condición de vida de sus habitantes considerando que los ingresos económicos y condiciones de vivienda, así como la cobertura de servicios se han mejorado, con lo que es posible afirmar que los programas sociales son, hasta el momento, exitosos (Secretaría de Desarrollo Social, 2004).

La Ciudad de México es una de las entidades con menor porcentaje de su población en situación de pobreza y rezago social, sin embargo, el origen, así como su modo de urbanización repercute en el desarrollo del territorio y, por lo tanto, en las oportunidades para mejorar el espacio.

Concretamente, las áreas verdes de las alcaldías de estudio tienen grandes diferencias en cuanto a cantidad, calidad y distribución, ya que, como se demostró, la DMH cuenta con mayor cantidad de estos espacios, en parte gracias al bosque de Chapultepec, sin embargo, aun si no se contara con este espacio la cantidad de parques es mucho mayor a comparación de la DI.

De esta manera, los resultados demostraron que existe una concentración de las AVU de la ciudad en ciertos territorios, en este caso la DMH. Por lo que la población de las alcaldías de estudio no cuenta con el mismo nivel de acceso y disfrute de estos espacios, para corroborarlo basta ver el índice de AV/H de cada alcaldía. Por ello, aunque la ciudad tenga un índice total de área verde por habitante aceptable, no significa que la distribución de estos espacios sea equitativa.

Los servicios ambientales y sociales tampoco son iguales en los distintos territorios, lo que puede provocar el deterioro social en zonas específicas (en este caso la DI). Estos resultados concuerdan con lo mencionado por Fernández-Álvarez (2017), quien menciona que la distribución y accesibilidad de las AVU está fuertemente sesgada contra las poblaciones marginadas ya que las características socioeconómicas de la población están directamente relacionadas con la cantidad metros cuadrados de áreas verdes por habitantes.

En el caso de las alcaldías de estudio ya se mencionó que actualmente estas brechas sociales se han reducido, sin embargo, las distintas maneras de urbanización de ambos territorios son factores que limitan (AIZ) o favorecen (AMH) la capacidad de aumentar sus AVU.

Adicionalmente, el deterioro de las AVU significa una grave problemática para la ciudad entera, ya que los beneficios generados por la vegetación sirven para reducir la huella ecológica y mejorar la calidad de vida en ella. En este sentido, los esfuerzos de la Ciudad de México deben ir dirigidos en lograr un bienestar y equidad social que se refleje de manera homogénea en su territorio, considerando factores como calidad de vida, movilidad, ingresos, servicios, calidad ambiental y acceso a áreas verdes.

Los resultados muestran que la distribución de las áreas verdes en la ciudad, considerando las alcaldías de estudio, es desigual y muestran distintas condiciones tanto de superficie como de cobertura vegetal por lo que los programas de manejo y mejoría no están cumpliendo (en todo el territorio) con sus funciones. Esto implica que deben aumentarse los esfuerzos gubernamentales, académicos y sociales para contrarrestar esta desigualdad (Fernández-álvarez, 2017). Por ello el objetivo de ser una ciudad verde, incluyente y equitativa para todos los habitantes se encuentra aún lejano para la CDMX.

Finalmente es importante mencionar que este trabajo puede ser una base para desarrollar un sistema de monitoreo del progreso en materia de conservación y mejora de AVU, ya que la metodología establecida permite la comparación temporal, lo que facilita la planeación y gestión de AVU. Por último, los resultados podrían ser más claros si se utilizan imágenes 
satelitales con mayor resolución con las que se puede estimar con mayor precisión las condiciones de la vegetación de estos espacios.

\section{LITERATURA CITADA}

Aguilar Arias, H., Mora Zamora, R., \& Vargas Bolaños, C. (2014). Metodología para la corrección atmosférica de imágenes Aster, RapidEye, Spot 2 y Landsat 8 con el módulo Flaash del Software ENVI. Revista Geográfica de América Central, Julio$\operatorname{dici}(53), 39-59$.

Aguilar, N., Galindo, G., Fortanelli, J., \& Contreras, C. (2010). Índice normalizado de vegetación en caña de azúcar en la Huasteca Potosina. Avances En Investigación Agropecuaria, 14(2), 49-65.

Aldana, D., Anges, T., \& Bosques Sendra, J. (2008). Cartografía de la cobertura / uso de la tierra del Parque Nacional Sierra de La Culata, estado Mérida-Venezuela. Revista Geográfica Venezolana, 49(2), 173-200.

AlMomento.mx. (2017). Presentan denuncia popular por impacto ambiental en obra de Mixcoac. Retrieved July 9, 2017, from https://almomento.mx/presentan-denunciapopular-por-impacto-ambiental-en-obra-de-mixcoac/

Ancira-sánchez, L., \& Treviño Garza, E. J. (2015). Utilización de imágenes de satélite en el manejo forestal del noreste de México. Madera y Bosques, 21(1), 77-91.

Asamblea Legislativa del Distrito Federal VI Legislatura. Ley de Salvaguarda del Patrimonio Urbanístico Arquitectónico del Distrito Federal. , (2014).

Atiqul Haq, S. M. (2011). Urban Green Spaces and an Integrative Approach to Sustainable Environment. Journal of Environmental Protection, July(2), 601-608.

Benítez, G., Chacalo, A., \& Barois, I. (1987). Aportes A La Ecologia Urbana De La Ciudad De Mexico. In E. H. Rapoport \& I. R. López-Moreno (Eds.), Aportes a la Ecología Urbana de la Ciudad de México (Limusa, pp. 193-201). Ciudad de México.

Berlin.de. (n.d.). Senate Department for the Environment, Transport and Climate Protection. Retrieved from Urban Green Space website: https://www.berlin.de/senuvk/natur_gruen/index_en.shtml

Bolin, B., Matranga, E., Hackett, E. J., Sadalla, E. K., Pijawka, K. D., Brewer, D., \& Sicotte, D. (2000). Environmental equity in a sunbelt city: the spatial distribution of toxic hazards in Phoenix, Arizana. Global Environmental Change Part B: Environmental Hazards, 2(1), 11-24.

Bolivar Espinoza, G. A., \& Caloca Osorio, O. R. (2011). Distribución espacial de la pobreza . Distrito Federal de México 1990-2040. Polis: Revista Latinoamericana, 2011(29), 1-29.

Consejo Nacional de Evaluación de la Politica de Desarrollo Social. (2013). Informe de pobreza y evaluación. Ciudad de México.

Cvejić, R., Eler, K., Pintar, M., Zeleznikar, S., Haase, D., Kabisch, N., \& Strohbach, M. (2015). A typoligy of urban green spaces, ecosystem provisioning services and demands (Vol. 10).

Departamento de Ordenación del Territorio y Medio Ambiente. (2003). Criterios de sostenibilidad aplicables al planeamiento urbano. Serie Programa Marco Ambiental, $\operatorname{Mayo}(22), 46$.

Fan, Y., Das, K., \& Chen, Q. (2011). Neighborhood green, social support, physical activity, and stress: Assessing the cumulative impact. Health and Place, 17(6), 571-582.

Fernández-álvarez, R. (2017). Inequitable distribution of green public space in the Mexico City: an environmental injustice case. Economía, Sociedad y Territorio, 42(54), 399-428.

Flores-Xolocotzi, R. (2012). Incorporando desarrollo sustentable y gobernanza a la gestión y planificación de áreas verdes. Frontera Norte, 24(48), 165-190.

Flores-Xolocotzi, R., \& Gonzáles-Guillen, M. de J. (2010). Planificación de Sistemas de áreas verdes y parques públicos. Revista Mexicana de Ciencias Forestales, 1(1), 17-24.

Gaceta Oficial del Distrito Federal. (1999). Decreto de Presupuesto de Egresos del Distrito Federal Para el Ejercicio Fiscal 2000. Administración Pública Del Distrito Federal, 75-79. 
Gaceta Oficial del Distrito Federal. (2009). ). Decreto de Presupuesto de Egresos del Distrito Federal Para el Ejercicio Fiscal 2010. Administración Pública Del Distrito Federal, 3-31.

Gaceta Oficial del Distrito Federal. (2014). Decreto de Presupuesto de Egresos del Distrito Federal Para el Ejercicio Fiscal 2015. Administración Pública Del Distrito Federal, 19-23.

Galindo-Bianconi, A. S., \& Victoria-Uribe, R. (2012). La vegetación como parte de la sustentabilidad urbana: beneficios, problemáticas y soluciones para el Valle de Toluca. Quivera, 14(1), 98-108.

Gómez Gutiérrez, C. (2014). El desarrollo sostenible: Conceptos básicos, alcances y criterios para su evaluación. In Cambio Climático y Desarrollo Sostenible: Bases conceptuales para la educación en Cuba (Educación). La Habana.

Gonzales-Elizondo, S., Gonzales-Elizondo, M., \& Cortes-Ortiz, A. (1993). Vegetación de la Reserva de la Biosfera "La Michila”, Durango, México. Acta Botánica Mexicana, 22, $1-104$.

Grant, L. (2010). Multi-Functional Urban Green Infrastructure. London, U.K.

Guzmán, Á. vega, López-García, J., \& Manzo Delgado, L. de L. (2008). Análisis espectral y visual de vegetación y uso del suelo con imágenes Landsat ETM + con apoyo de fotografías aéreas digitales en el Corredor Biológico Chichinautzin, Morelos, México. Investigaciones Geográficas, Boletin Del Instituo de Geografía, UNAM, 1(67), 59-75.

Handley, J. (2003). Accessible Natural Green Space. Standards in Towns and Cities: A review and Toolkit for their Impementation. Peterborough.

Hernández Flores, maría de la L., Palacios Romero, A., Otazo Sánchez, E., \& Mendoza Herrera, K. A. (2016). Influencia de la urbanización en el cambio de la vegetación colindante del corredor Pachuca-Tizayuca ( 2000-2014 ). Revista Mexicana de Ciencias Forestales, 7(33), 20-39.

Hinojosa Robles, E. (2014). El manejo de áreas verdes en la Ciudad de México y Pekín : la búsqueda de la sustentabilidad en grandes ciudades. Investigación Ambiental, 6(1), 69-77.

Instituto Nacional de Estadística Geografía e Informática. (1997). Los Hogares en México (Primera). Aguascalientes.

Instituto Nacional de Estadística Geografía e Informática. (2000). XII Censo General de población y Vivienda 2000 (INEGI). Aguascalientes.

Instituto Nacional de Estadística Geografía e Informática. (2002). Producto Interno Bruto por Entidad Federativa 1997-2002 (INEGI). Ciudad de México.

Instituto Nacional de Estadística Geografía e Informática. (2011). Principales resultados del censo del censo de población y vivienda 2010 (INEGI). Aguascalientes.

Instituto Nacional de Estadística Geografía e Informática. (2015a). Anuario estadístico y geográfico del Distrito Federal 2015 (INEGI). Ciudad de México.

Instituto Nacional de Estadística Geografía e Informática. (2015b). Principales resultados de la encuesta intercensal 2015 (Primera). Aguascalientes.

Instituto Nacional de Estadística Geografía e Informática. (2017). Banco de Información Eonómica. Retrieved April 26, 2017, from https://www.inegi.org.mx/sistemas/bie/?idserPadre=10200070\#D10200070

Jennings, V., Larson, L., \& Yun, J. (2016). Advancing Sustainability through Urban Green Space: Cultural Ecosystem Services, Equity, and Social Determinants of Health. International Journal of Environmental Research and Public Health, 13(196), 15.

Jiménez Pérez, J., Cuéllar, G., \& Treviño, E. (2013). Áreas Verdes del Municipio de Monterrey. Monterrey.

Kendal, D., Lee, K., Ramalho, C., Kathryn, B., \& Bush, J. (2016). Benefits of Urban Green Space in the Australian Context. Melbourne.

López, E. (2013). Beneficios en la implementación de áreas verdes urbanas para el desarrollo de ciudades turísticas. Topofilia: Revista de Arquitectura, Urbanismo y Ciencias Sociales, IV(1), 16.

Maas, J., Van Dillen, S., Vertheij, R., \& Groenewegen, P. (2009). Social contacts as a posible mechanism behind the relation between green space and healt. Health and Place and Place, 15(2), 586-595. 
Meneses-Tovar, C. L. (2011). El índice normalizado diferencial de la vegetación como indicador de la degradación del bosque. Unasylva: Revista Internacional de Silvicultura e Industrias Forestañes, 62(238), 72.

Municipio de Durango. (2006). Plan Director de Forestación Urbana del Municipio de Durango. Gaceta Municipal, XXII(165), 41.

Observatorio de Medio Ambiente Urbano. (2015). Agenda 21 Málaga 2015: Agenda urbana en la estrategia de sostenibilidad integrada 2020-2050. Malaga.

ONUHabitat. (2016). Índice básico de las ciudades prosperas: Miguel Hidalgo. Ciudad de México.

Peña Araya, M. A. (2007). Correcciones de una imagen satelital ASTER para estimar parámetros vegetacionales en la cuenca del río Mirta , Aisén. Bosque, 28(2), 162-172.

Pérez-Medina, S., \& López-Falfán, I. (2015). Áreas verdes y arbolado en Mérida , Yucatán . Hacia una sostenibilidad urbana. Economía, Sociedad y Territorio, xv(47), 1-33.

Procuraduria Ambiental y de Ordenamiento Territorial. (2010). Presente y Futuro de las Áreas Verdes y del Arbolado de la Ciudad de México (Ekilibria). Ciudad de México.

Ramos-Reyes, R., Palma-López, D., Ortiz-Solorio, C. A., Ortiz-Garcia, C. F., \& Díaz-Padilla, G. (2004). Cambios de uso de suelo mediante técnicas de sistemas de información geográfica en una región cacaotera. Terra Latinoamericana, 22(3), 267-278.

Reyes Päcke, S., \& Figueroa Aldunce, I. M. (2010). Distribución , superficie y accesibilidad de las áreas verdes en Santiago de Chile. EURE, 36(109), 89-110.

Rivera, N. (2002). En la casa de la Sal: monografia, cronicas y leyendas de Iztacalco (Gobierno d). Ciudad de México.

Salvador Palomo, P. J. (2003). La planificación verde en las Ciudades (G. Gili, Ed.). Madrid.

Sánchez, M. (2015). EL DF PIERDE EN 15 AÑOS 56 MIL ÁRBOLES POR OBRAS. Retrieved June 13, 2017, from SinEmbargo website: http://www.sinembargo.mx/24$05-2015 / 1353514$

Secretaría de Desarrollo Social. (2004). Pobreza, Desigualdad y Marginación en la Ciudad de México (Dirección). Ciudad de México.

Secretaría de Desarrollo Urbano y Vivienda. (2008a). Programa Delegacional de Desarrollo Urbano de Miguel Hidalgo. Gaceta Oficial Del Distrito Federal, p. 169.

Secretaría de Desarrollo Urbano y Vivienda. (2008b). Programa Delegacional de Desarrollo Urbano para la Delegación Iztacalco. Gaceta Oficial Del Distrito Federal, p. 136.

Secretaría del Medio Ambiente. (2003). Inventario de áreas verdes del Distrito Federal (SEDEMA). Ciudad de México.

Secretaría del Medio Ambiente. (2012a). AGENDA AMBIENTAL DE LA CIUDAD DE MÉXICO Programa de Medio Ambiente 2007-2012. Ciudad de México.

Secretaría del Medio Ambiente. (2012b). Plan verde de la Ciudad de México: 5 años de avances. Ciudad de México.

Secretaría del Medio Ambiente. (2015a). CDMX Sustentable: verde, movil, educativa, recreativa (Primera; S. Soto Lemus, Ed.). Ciudad de México.

Secretaría del Medio Ambiente. (2015b). NADF-001-RNAT-2015. Retrieved from Gaceta Oficial Del Distrito Federal website: http://www.paot.org.mx/centro/normas_a/2016r/NADF-001-RNAT2015_PODA_DERRIBO_TRASPLANTE_01_04_2016.pdf

Secretaría del Medio Ambiente. (2016). Ciudad verde, Ciudad viva. Retrieved July 4, 2016, from http://data.sedema.cdmx.gob.mx/sedema/index.php/ciudad-verde

Secretaría del Medio Ambiente. (2017). Programa de Reforestación Urbana. Retrieved from http://data.sedema.cdmx.gob.mx/reforestacion-urbana/index.html

Sherer, P. M. (2003). The Benefits of Parks : Why America Needs More City Parks and Open Space. The Trust for Public Land, 32.

Sierra Rodríguez, I., \& Ramírez-Silva, J. P. (2010). Los parques como elementos de sustentabilidad de las ciudades. Revista Fuente, 2(5), 6-14.

Sorensen, M., Barzetti, V., \& Williams, J. (1998). Manejo de las áreas verdes urbanas. Washington, D.C.

Soria Ruiz, J., \& Granados Ramírez, R. (2005). Relación entre los índices de vegetación 
Recibido:

18/diciembre/2018

Aceptado:

14/junio/2019 obtenidos de los sensores AVHRR del satélite NOAA y TM del Landsat. Ciencia Ergo Sum, 12(2), 167-174.

Trucíos-Caciano, R., Estrada-Ávalos, J., Cerano-Paredes, J., \& Rivera-Gonzáles, M. (2011). Interpretación del Cambio en Vegetación y Uso de Suelo. Terra Latinoamericana, 29(4), 359-367.

UnHabitatIII. (2016). URBANIZATION AND DEVELOPMENT (Primera; United Nations Human Settlements Programe, Ed.). Nairobi.

Vera, R. (2014). Tren México-Toluca: Ecocidio, descontento social... y los mismos socios del poder. Retrieved July 13, 2017, from Proceso.com.mx website: https://www.proceso.com.mx/391895/tren-mexico-toluca-ecocidio-descontento-socialy-los-mismos-socios-del-poder-2

World Health Organization. (2016). Urban green spaces and health: A review of evidence. Copenhagen. 